\title{
Can Trucks Sustain the Objective Force Army?
}

\author{
A Monograph \\ by \\ MAJ Jason R Vick \\ US Army
}

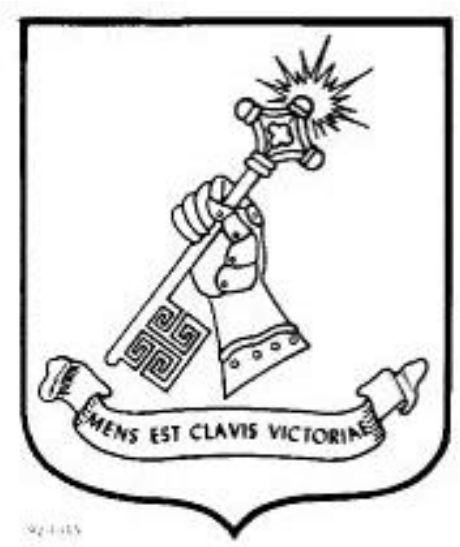

School of Advanced Military Studies

United States Army Command and General Staff College

Fort Leavenworth, Kansas

AY 01-02 


\section{SCHOOL OF ADVANCED MILITARY STUDIES MONOGRAPH APPROVAL}

MAJ J ason R. Vick

Title of Monograph: Can Trucks Sustain the Objective Force Army?

Approved by:

COL Richard Proietto

Monograph Director

Professor and Director Academic Affairs, School of Advanced Military Studies

Director, Graduate Degree

Philip J. Brookes, Ph.D. Program 


\section{ABSTRACT}

\section{CAN TRUCKS SUSTAIN THE OBJECTIVE FORCE ARMY?, BY MAJOR JASON R. VICK, USA, 71 PAGES.}

This monograph examines the Army's future operational level logistic support in an effort to determine whether or not the Army can successfully execute its Objective Force transformation without an aerial-based sustainment and distribution system. The Objective Force is the Army's futuristic medium-weight, motorized force that will have an operational reach of 1,000 kilometers in any direction. Sustaining this force will require maneuver sustainment organizations with equal or greater combat service support (CSS) reach. Although the Objective Force exists only as a concept, its design will be guided by seven design characteristics: responsiveness, deployability, agility, versatility, lethality, survivability and sustainability. The author evaluates how well a sustainment concept might support the Objective Force with an assessment of these characteristics.

The future relevance of the Army was the impetus for change and transformation efforts. The Army is becoming more strategically responsive by reducing its size and support requirements while increasing its effectiveness. The Objective Force operational environment will not allow entry into the theater through ports of debarkation and will have extended and unsecured lines of communication. The Objective Force will conduct operational maneuver from strategic distances and arrive in the area of operations ready to fight. Operations will commence without in-theater sustainment bases. During continuous operations, Objective Force units will be able to selfsustain for three to seven days without external replenishment. This will create new challenges for the Army's sustainment community.

Objective Force maneuver sustainers must provide rapid and assured support throughout the theater, without relying on logistics mass. The sustainment system will be based on a high velocity distribution pipeline. Objective Force sustainers will have unprecedented situational awareness and predictive knowledge of maneuver force logistics requirements. Even with increased information and reduced demands, this will eventually translate into an order to move supplies. These supplies will traverse extended distances on a distributed battlefield. Current and proposed distribution methods are evaluated within the context of this future operational environment to determine what transportation modes best support Objective Force operations.

Available surface or air modes will limit Objective Force maneuver sustainment reach operations. Objective Force sustainers will use familiar criteria such as METT-TC to select the transportation mode. However, reducing the CSS footprint in the battle space will also heavily influence this decision because it is the overarching concept for CSS Transformation. As distances between supported and supporting forces increase, ground transit times may actually increase the CSS footprint and presence.

Historical examples of aerial sustainment are cited with emphasis on sustainment to Army forces at the operational level. The author contends that the Army must make aerial sustainment a core competency of Objective Force maneuver sustainment organizations. The author offers changes in culture, organizations and materiel to facilitate transforming Army maneuver sustainment. The Army should maintain its surface transportation capabilities, but organic aerial sustainment is a must in order to support high intensity and rapid Objective Force operations. 


\section{TABLE OF CONTENTS}

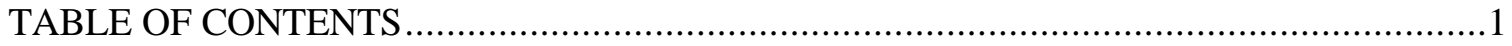

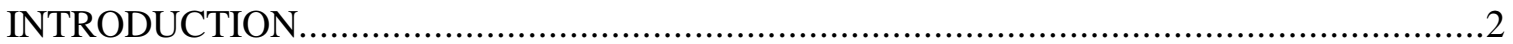

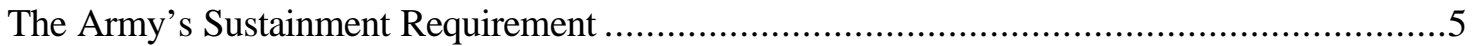

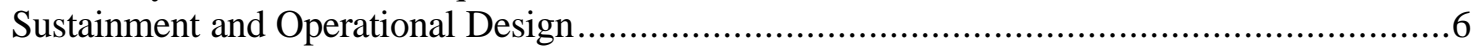

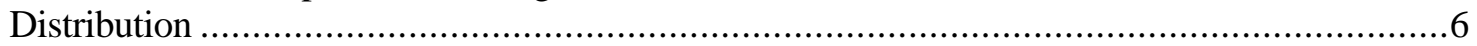

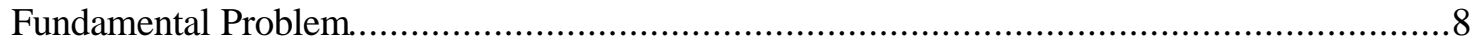

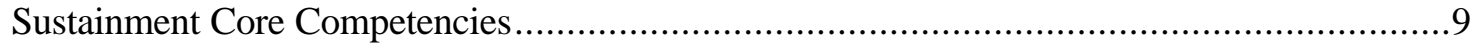

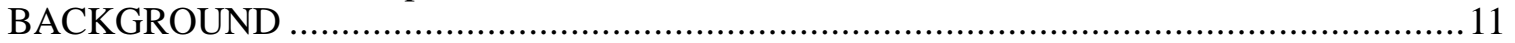

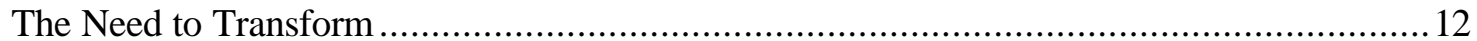

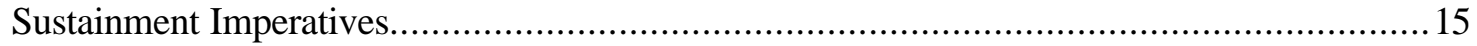

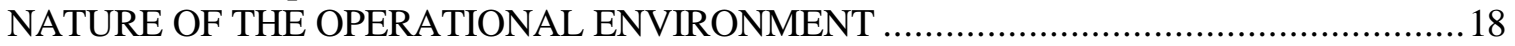

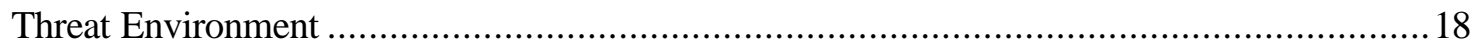

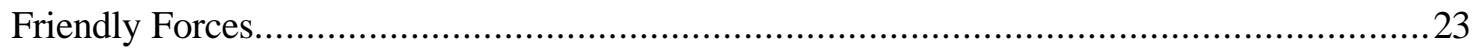



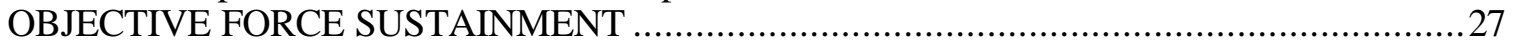

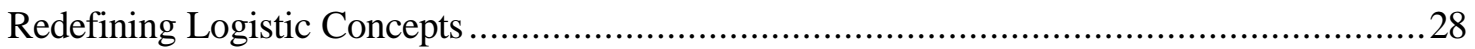

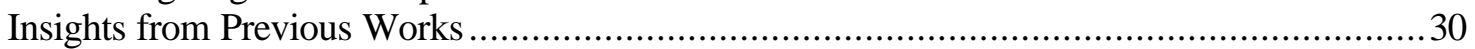

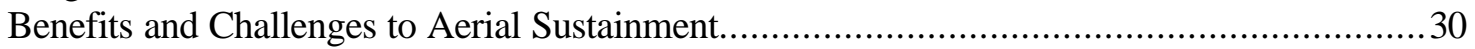

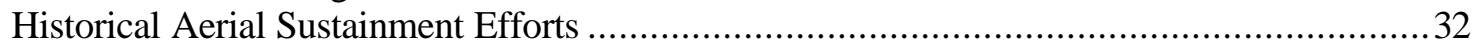

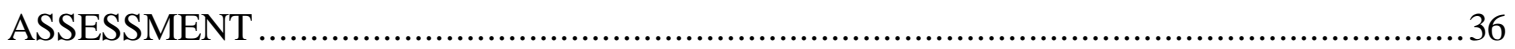

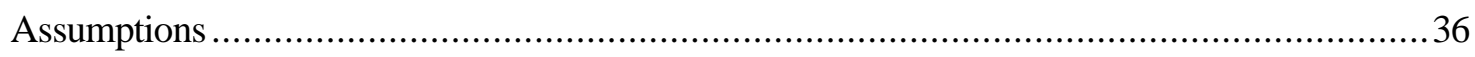

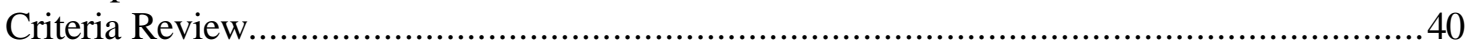

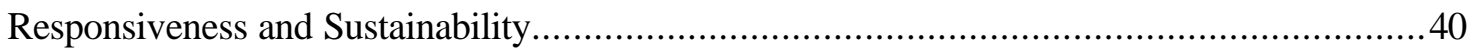

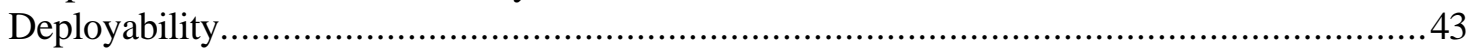

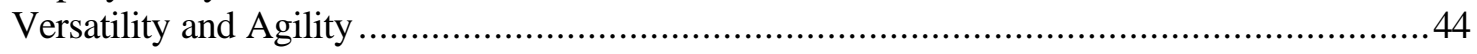

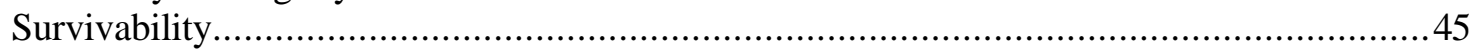

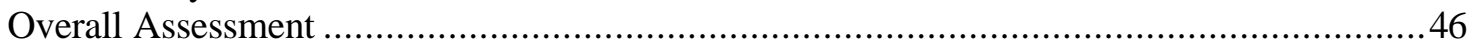

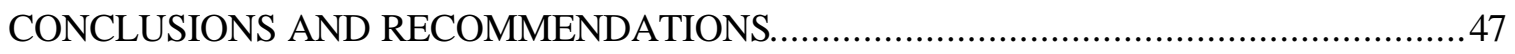

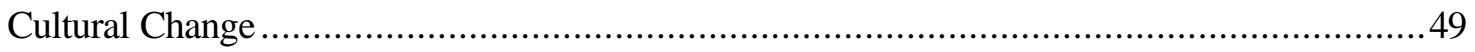

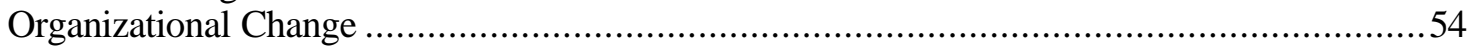

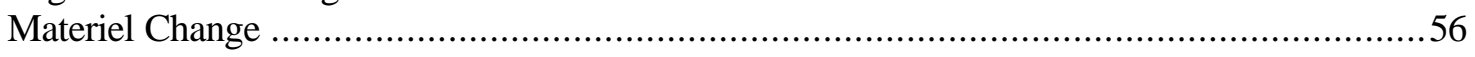

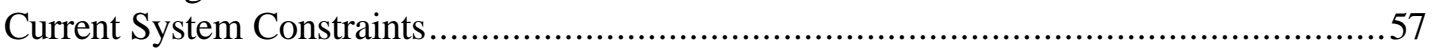

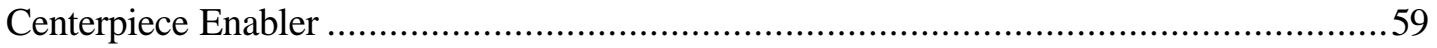

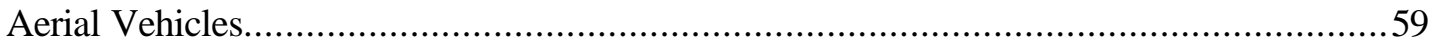

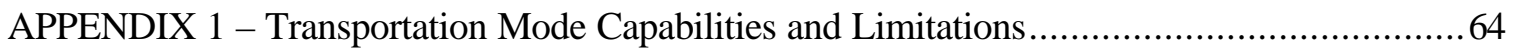

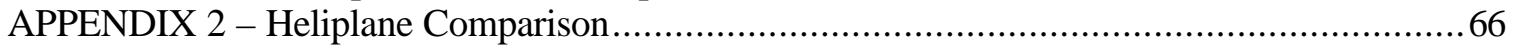

APPENDIX 3 Legacy Force CSS and Associated Maneuver Commander .............................68

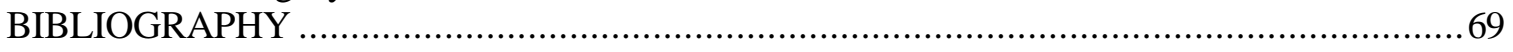




\section{CHAPTER ONE}

The goal of Army CSS is to enable the commander to execute his mission and sustain the force.

Department of the Army, FM 100-10, Combat Service Support

\section{INTRODUCTION}

The US Army is currently undergoing a transformation from its current legacy force to the Objective Force. Army Chief of Staff, General Erik Shinseki, provided the vision for the Objective Force concept and he is trying to field the first units this decade. ${ }^{1}$ By $2015,15 \%$ of the Army will have transformed with the remainder completed in following decades. ${ }^{2}$ Making predictions about how the Objective Force will fight and sustain is difficult because of the time horizon and many of the enabling technologies and doctrinal concepts are emerging or do not yet exist. Furthermore, there are significant barriers to change that the Army and Department of Defense have not fully addressed. ${ }^{3}$

Since the Objective Force is in the concept phase, there is no available data on force structure from which to determine supply consumption factors. Also, there were no obtainable models to simulate logistic requirements. Therefore, it is impossible to reliably determine how much and which types of supplies Objective Force units will need. This monograph is necessarily conceptual and considers whether the Army can successfully execute its Objective Force transformation without an aerial based sustainment and distribution system. As the Objective Force concept matures, detailed analysis using reliable logistic data may be possible.

\footnotetext{
${ }^{1}$ Eric K. Shinseki, "CSA Remarks," Speech presented to the Association of the United States Army Seminar. Washington, DC. 8 Nov. 2001. http://www.army.mil/leaders/csa/speeches/20011108CSAREMARKSAUSA.doc, 2.

${ }^{2}$ United States Army Training and Doctrine Command. TRADOC Pamphlet 525-4-0, The United States Army Objective Force Maneuver Sustainment Operational and Organizational (O\&O) Concept (Draft 11 Feb 2002). By CASCOM CSS Battle Lab. Fort Monroe, 2002, 19.

${ }^{3}$ The Objective Force is a concept. The Chief of Staff of the Army has provided a vision for the characteristics of the Objective Force, but the Army has not implemented the programs required to actually field the force. Achieving the Objective Force will not only require transforming the Army, but the Department of Defense as well. Many of these issues remain unresolved.
} 
The Army is aggressively pursuing efforts to make the Objective Force a reality. Some of these efforts include scientific research and a series of Army Transformation war games whose results help to further define the Objective Force. Nevertheless, the Army has yet to publish any doctrinal references. The primary documents that describe the Objective Force are the Objective Force White Paper, Army Vision, Army Transformation War Game (ATWG) After Action Reviews (AAR), and draft Training and Doctrine Command (TRADOC) publications. These documents describe it as a futuristic medium-weight, mounted force with fewer logistics requirements, but far greater operational reach and endurance than current legacy forces. ${ }^{4}$

Although the Objective Force currently exists only as a concept, its development will be guided by seven design characteristics: responsiveness, deployability, agility, versatility, lethality, survivability and sustainability. ${ }^{5}$ The Objective Force White Paper describes these characteristics from the perspective of Objective Force combat formations, but they apply to all aspects of the Objective Force. An evaluation of how well a sustainment concept might support the Objective Force must include an assessment of these characteristics. From a sustainment standpoint, they are defined as follows:

Responsiveness: The ability to employ the right sustainment force that can provide the right support in the right place at the right time.

Deployability: The ability to prepare and move a force and its sustainment equipment and supplies to the area of operations.

Agility: The ability of friendly forces to rapidly adapt sustainment structures and procedures to changing mission requirements and to act faster than the enemy.

Versatility: The ability to rapidly and effectively shift focus from one operation to the other to support Objective Force mission transitions.

Lethality: The ability to generate and sustain combat power.

\footnotetext{
${ }^{4}$ The key materiel enabler to the Objective Force is the Future Combat System (FCS) that will be designed to weigh 20 tons. This will make the Objective Force heavier than current light forces, but lighter than mechanized or heavy forces. The Army will design the Objective Force to conduct mounted operations without sustainment for three to seven days versus one day for current forces. The technologies that will allow for FCS production are emerging, but expected in the near future.

${ }^{5}$ Department of the Army. White Paper: Concepts for the Objective Force. Washington, DC, 2001. 12 Nov. $2001<$ http://www.army.mil/features/WhitePaper/ObjectiveForceWhitePaper.pdf>, 6.
} 
Survivability: The ability to protect support functions from destruction or degradation.

Sustainability: The ability to provide minimum essential sustainment to begin operations while providing continuous support throughout operations. ${ }^{6}$

Achieving a force with the above design characteristics will require a paradigmatic shift in how the Army's maneuver sustainment organizations manage information and physically provide materiel. ${ }^{7}$ The Army's primary method of sustaining its forces involves the use of surface transportation modes between in-theater sustainment bases. ${ }^{8}$ The consequence of this system is in-theater stocks and the requirement for ground lines of communication connecting the sustainment to the supported force. The Army is making great strides in improving logistics information technology to provide predictive and real-time information on sustainment requirements. ${ }^{9}$ These efforts have and will continue to reduce, but not eliminate the requirement for some in-theater stocks. More than information management, the greater challenge will be to solve the problem of physical distribution of supplies to Objective Force units.

In the Objective Force era, supplies will traverse greater physical distances across a distributed battlefield. The maneuver sustainment system providing support in this environment will consist of soldiers, empowered by information and enabled by advanced distribution technologies. Distribution will occur via surface and aerial transportation modes. Surface distribution modes may be impracticable because of required infrastructure and relatively slower speeds compared to aerial modes. ${ }^{10}$ To overcome these challenges and meet support

\footnotetext{
${ }^{6}$ The author derived these evaluation criteria from the Objective Force White Paper, Joint Vision 2020, Joint Publication 4-0, FM 3-0, Chapter 12, and TRADOC Pamphlet 525-4-0.

${ }^{7}$ TRADOC Pamphlet 525-4-0 introduces new Objective Force sustainment concepts that are significantly different from legacy forces. The CSS footprint in the Objective Force combat zone will be reduced and sustainment will traverse much greater distances than legacy forces. Patterns of resupply will change from daily to once every three to seven days. This will require comprehensive improvements in information management and supply distribution.

${ }^{8}$ Department of the Army. Field Manual 55-1 Transportation Operations. Washington, DC, 1995, 5-6.

${ }^{9}$ United States Army. CASCOM After Action Report (AAR) for Army Transformation War Game 2001 (ATWG 2001). Fort Lee: CASCOM, 2001, 3.

${ }^{10}$ See Appendix 1 for a comparison of the advantages and disadvantages of various modes.
} 
requirements, the Army may need an aerial-based sustainment and distribution system to successfully execute its Objective Force transformation.

\section{The Army's Sustainment Requirement}

A primary function of the Army is, "to organize, train, and equip forces for the conduct of prompt and sustained combat operations on land--specifically, forces to defeat enemy land forces and to seize, occupy and defend land areas." 11 To conduct this primary function, the Army must be capable of sustaining itself. This function is common to all of the Armed Services as they are responsible for, "providing logistic support for Service forces, including procurement, distribution, supply, equipment, and maintenance, unless otherwise directed by the Secretary of Defense." ${ }^{12}$ At the operational level, sustaining Army forces occurs from theater ports of debarkation (POD) to supported forces. Army sustainment organizations provide support using sustainment bases, transportation modes and lines of communication (LOC).

The Army has additional operational sustainment responsibilities to provide certain support to other forces as directed. ${ }^{13}$ Although these requirements have an impact on the Army, they are beyond the scope of this monograph. The focus of this monograph is operational level support that will enable the Army's Objective Force to conduct prompt and sustained land combat operations.

The scope, range and methods of providing operational level support can vary greatly depending on the environment. Since the Objective Force will be able to fight anywhere in the world across the spectrum of operations, maneuver sustainers will have varying requirements. Some theaters may have established ports and roads and others may not. For the purpose of study and evaluation, this monograph will assume an operational environment that will not allow entry through ports of debarkation, has limited external support availability with uncertain lines of

\footnotetext{
${ }^{11}$ Department of Defense. Directive Number 5100.1: Functions of the Department of Defense and Its Major Components. By Deputy Secretary of Defense. Washington, DC, 1987, 17.

${ }^{12}$ Ibid., 15.

${ }^{13}$ Ibid., 18.
} 
communication. If the Objective Force can conduct operations and sustain in a worst-case environment, sustainment in a permissive scenario should be practicable.

\section{Sustainment and Operational Design}

Objective Force maneuver sustainers will sustain major operations with greater operational reach than current forces. For example, a 1980s Army corps had an operational reach of about 300 kilometers, but an equivalent Objective Force unit will have an operational reach over three times as long. ${ }^{14}$ Good operational design ensures that maneuver units have sufficient operational reach to achieve objectives before culmination. ${ }^{15}$ Sustainment and distribution are key combat service support (CSS) concepts that directly contribute to maneuver force capabilities.

Sustainment is, "the provision of personnel, logistic, and other support required to maintain and prolong operations or combat until successful accomplishment or revision of the mission or of the national objective." ${ }^{, 16}$ At the operational level, logistic units maintain and supply Army forces with the purpose of facilitating accomplishment of the combatant commander's mission. A constant flow of materiel to theater sustainment bases enables logisticians to conduct sustainment activities. While the Army has made progress in making logistics more efficient and effective, echelons of supply are still required. In the Objective Force era, the sustainment system will be based on distribution. ${ }^{17}$

\section{Distribution}

The theater distribution system facilitates sustaining Army forces. This system is, "comprised of four independent and mutually supported networks within theater to meet the geographic combatant commander's requirements; the physical network; the financial network; the

\footnotetext{
${ }^{14}$ United States Army. CASCOM After Action Report (AAR) for Army Transformation War Game 2001 (ATWG 2001). Fort Lee: CASCOM, 2001, 12

${ }^{15}$ Department of the Army. Field Manual 3-0 Operations. Washington, DC, 2001, 5-10.

${ }^{16}$ Department of Defense. Joint Publication 1-02, Department of Defense Dictionary of Military and Associated Terms . By Chairman of the Joint Chiefs of Staff. Washington, D.C.: US Government Printing Office, 2001, 423.
} 
information network; and the communications network." "Distribution relates to the CSS pipeline activities associated with sending, moving, and receiving resources." ${ }^{\text {19 }}$ Distribution is not a separate function, but rather a complex function synchronized throughout the supply chain.

Joint Publication 4-0 defines distribution as, "the operational process of synchronizing all elements of the logistics system to deliver the 'right things' to the 'right place' at the 'right time,' to support the combatant commander." ${ }^{20}$ Many factors make distribution possible, but transportation mode operations as they relate to materiel management are one of the most significant. Integrated planning and information systems facilitate knowing the time and location items supporting an operation need to be delivered, but eventually this is translated into an order to physically move something. Air and surface are the available transportation modes and of the two, the Army primarily relies on surface modes to sustain the force. ${ }^{21}$

Surface transportation modes are preferable because they are the most efficient and depending on the time available, they can be the most effective. Surface modes provide the greatest lift capabilities, but require infrastructure such as roads, railways and inland waterways. ${ }^{22}$ Army forces can develop or improve these lines of communication if they are not available in theater, but this effort requires considerable time and resources. Furthermore, surface modes are vulnerable to enemy interdiction because of the predictability of using ground lines of communication. A contributing cause of the Russians' defeat in Afghanistan during their

\footnotetext{
${ }^{17}$ United States Army Training and Doctrine Command. TRADOC Pamphlet 525-4-0, The United States Army Objective Force Maneuver Sustainment Operational and Organizational (O\&O) Concept (Draft 11 Feb 2002). By CASCOM CSS Battle Lab. Fort Monroe, 2002, 8.

${ }^{18}$ Department of Defense. Joint Publication 1-02, Department of Defense Dictionary of Military and Associated Terms . By Chairman of the Joint Chiefs of Staff. Washington, D.C.: US Government Printing Office, 2001, 438.

${ }^{19}$ Department of the Army. Field Manual 100-10 Combat Service Support. Washington, DC, 1995, 2-11.

${ }^{20}$ Department of Defense. Joint Publication 4-0 Doctrine for Logistics Support of Joint Operations. By Director for Logistics (J-4). Washington, DC, 2000, 1-15.

${ }^{21}$ Department of the Army. Field Manual 100-10-1 Theater Distribution. Washington, DC, 1999, C-17.

${ }^{22}$ See Appendix 1 for a comparison of modes of transportation.
} 
occupation in the 1980 s was their inability to protect their ground lines of communication. ${ }^{23}$ Using air modes of transportation can alleviate some, but not all of these challenges.

Air modes of transportation have some advantages over surface modes. The Army uses CH47 Chinook helicopters and US Air Force fixed wing assets such as the C-130 and C-17 at the operational level. ${ }^{24}$ These aircraft have an extended reach and can rapidly deliver materiel throughout the theater without the constraints of ground lines of communication, but they have less capacity than surface modes and require significant infrastructure to sustain themselves. The key to success in sustaining the Objective Force will be to develop a distribution system that combines the advantages of air and surface transportation modes.

\section{Fundamental Problem}

The fundamental challenge to sustaining the Objective Force will be distribution of required sustainment throughout the battlefield. Three environmental factors contribute to this challenge:

- The depth of the battlefield and the operational reach of the Objective Force

- The operational tempo and requirement to bypass ports of debarkation

- The absence of a logistic build up

The sustainment and distribution system must enable the Objective Force to conduct full spectrum operations in the expected future environment. The Objective Force will be capable of operational maneuver from strategic distances. ${ }^{25}$ Future adversaries will employ anti-access strategies focused at air and sea ports of debarkation. ${ }^{26}$ The Objective Force will have to bypass

\footnotetext{
${ }^{23}$ Ali Ahmad Jalali and Lester W. Grau. The Other Side of the Mountain: Mujahideen Tactics in the Soviet-Afghan War. N.p., 1995, 147-148. Chapter 1 and Chapter 6 list several vignettes describing Mujahideen tactics for conducting ambushes and blocking Soviet lines of communication. The Soviets were repeatedly interdicted by relatively small Afghan forces and had to commit a significant amount of their combat power to the security mission. These forces were made unavailable for other missions. ${ }^{24}$ Department of the Army. Field Manual 55-1 Transportation Operations. Washington, DC, 1995, Chapter 5 .

${ }^{25}$ United States Army Training and Doctrine Command. TRADOC Pamphlet 525-3-0, The United States Army Objective Force Operational and Organizational Concept (Draft 11 Nov 01). Fort Monroe, 2001, 9. ${ }^{26}$ United States Army Training and Doctrine Command. Future Operational and Threat Environment: A View of the World in 2015. By Deputy Chief of Staff for Intelligence. Fort Monroe, 2001, 9.
} 
these ports of debarkation and arrive in theater ready to fight. ${ }^{27}$ This will require that the force is “optimized for rapid commitment on short notice to operations of uncertain scope and duration in immature theaters. ${ }^{, 28}$ Since the Objective Force can be committed early; there will be no time for a logistic build up in theater, but the sustainment system must be capable of supporting this force.

\section{Sustainment Core Competencies}

Sustained land dominance is an Army core competency. A key supporting competency, enabled by CSS forces, is to conduct sustainment operations. ${ }^{29}$ FM 3-0 states that, "CSS is an enabling operation that generates and sustains combat power..." ${ }^{130}$ Combat power results from the combination of maneuver, firepower, leadership, protection and information. ${ }^{31} \mathrm{CSS}$ commanders generate and sustain combat power by synchronizing the movement of soldiers and materiel and providing friendly information to support the war fighting commander's operations. ${ }^{32}$ To accomplish this CSS mission, Army logistic units have certain capabilities, characteristics and core competencies. A core competency of current Army sustainment organizations is the ability to provide surface-based supply and transportation support to combat forces in a sustained land campaign. $^{33}$

The US Army's logistic capability is unique among armies in the world. No other force has the organic capability to project power to conduct a sustained land campaign like the US Army. However, the limited range and high consumption rates of Army weapons systems makes in-

\footnotetext{
${ }^{27}$ Department of the Army. White Paper: Concepts for the Objective Force. Washington, DC, 2001. 12 Nov. 2001 http://www.army.mil/features/WhitePaper/ObjectiveForceWhitePaper.pdf, 6.

${ }^{28}$ Ibid, 7.

${ }^{29}$ Department of the Army. Field Manual 1 The Army. Washington, DC, 2001, 22.

${ }^{30}$ Department of the Army. Field Manual 3-0 Operations. Washington, DC, 2001, 12-1.

${ }^{31}$ Ibid., 3-4.

${ }^{32}$ Ibid., 12-2.

33 There is no doctrine explicitly stating core competencies for the Army's sustainment community. Core competencies are essential and enduring skills and characteristics that are an Army organization's fundamental contribution to the war fight. The Army organized its sustainment organizations to provide support primarily using motor transport, rail, pipeline and inland waterways. They have successfully provided this support to the Army, other services and allies worldwide for over 200 years.
} 
theater sustainment bases and distribution networks linked primarily by surface transportation modes a necessity.

This style of war will change greatly as the Army transitions to the Objective Force. The expected pace of operations and future enemy strategies will militate against the Army establishing in-theater sustainment bases. Objective Force units will be highly mobile and have relatively lower consumption rates of fuel and ammunition than present day forces. Objective Force units will still require sustainment, but need fewer supplies dispersed over a greater distance than present day forces. The Army's maneuver sustainment organizations will have to develop new competencies to meet the requirements of this operational environment.

The purpose of this monograph is to determine whether the Army can execute its Objective Force transformation without an aerial-based sustainment and distribution system. Chapter 2 provides background on Army Transformation and Chapter 3 describes the nature of the Objective Force operational environment. Chapter 4 examines the implications for sustainment and distribution to the Objective Force and gives historical aerial sustainment examples. Chapter 5 is an assessment of aerial and surfaced based systems supporting the Objective Force. Finally, Chapter 6 is conclusions and recommendations. The emphasis is on what the Army can do now, and needed changes for the future. 


\section{CHAPTER TWO}

If you don't like change, you're going to like irrelevance even less.

Army Chief of Staff, GEN Eric K. Shinseki

\section{BACKGROUND}

"Until the end of the Cold War, a keystone of Army doctrine was forward presence." 34 The lack of a peer competitor and the decreased likelihood of conventional war caused the US to return forces to the continental United States (CONUS). In the early 1990s, the US Army began a transition from a forward deployed to a power projection army. "Power projection includes the ability of the United States armed forces to deploy air, land, and sea forces to any region in the world and sustain them for missions spanning the operational continuum." 35 Operations in the following decade demonstrated the Army's need for significant change to reach goals established in its doctrine.

Multiple deployments to small-scale contingencies (SSC), military operations other than war (MOOTW) and stability and support operations (SASO) characterized Army operations in the 1990s. Somalia, Haiti, Bosnia and Kosovo are examples. The deployment of Task Force Hawk to Operation Allied Force in 1999 illustrated some of the Army's problems with strategic responsiveness. ${ }^{36}$ Notwithstanding political constraints on the use of ground forces, US Air Force air power proved decisive in that conflict. The threat of a credible ground force contributed to the victory, but the joint force commander never employed Army forces. ${ }^{37}$ Change was clearly required.

\footnotetext{
${ }^{34}$ Department of the Army. Field Manual 100-10-1 Theater Distribution. Washington, DC, 1999, 1-1.

${ }^{35}$ Ibid., 1-2.

${ }^{36}$ Benjamin S. Lambeth, NATO'S Air War For Kosovo: A Strategic and Operational Assessment. Rand, 2001. 9 Mar. 2002 http://www.rand.org/publications/MR/MR1365/, 147-158.

${ }^{37}$ Wesley K. Clark, Waging Modern War. New York: PublicAffairs, 2001. In GEN Clark's concluding chapter, he recognized that NATO achieved its objectives using air power. He also felt that the threat of the employment of the Army's Task Force Hawk contributed to the victory.
} 


\section{The Need to Transform}

The need to ensure future relevance influenced Army Transformation efforts. Army Transformation built on the modernization efforts of the 1990s with a holistic plan to prepare for the future. ${ }^{38}$ The first theme from the Objective Force Task Force web site is that, " 21 st Century challenges dictate the need to build a 21st Century Army centered upon strategic and tactical responsiveness and enhanced lethality and survivability." 39 These challenges involve national security, shifts in global power and the pace and proliferation of technology. ${ }^{40}$ The current and future operating environment created a compelling need to change. The result was Army Transformation.

In 1999, the Chief of Staff of the Army (CSA) initiated Army Transformation to transform the Army from its current legacy force into the Objective Force. The Objective Force will be "strategically responsive and dominant at every point of the spectrum of operations." ${ }^{41}$ Achieving this force will require substantial and synergistic changes in the six Army imperatives: doctrine, training, leader development, organizations, material and soldiers (DTLOMS). ${ }^{42}$ Accordingly, the Objective Force Army will operate in a considerably different manner from today's Army.

The Objective Force will be a rapidly deployable and lethal medium-weight mounted force. This is in contrast to today's mix of heavy, light and air assault forces that require significantly more deployment lift and sustainment to operate. Objective Force units will have greater operational reach while requiring less sustainment. The key to achieving these Objective Force operational capabilities are major advances in science and technology that will reduce the demand

\footnotetext{
${ }^{38}$ Eric K. Shinseki, "CSA Remarks," Speech presented to the Association of the United States Army Seminar. Washington, DC. 8 Nov. 2001. http://www.army.mil/leaders/csa/speeches/20011108CSAREMARKSAUSA.doc, 2

${ }^{39}$ United States Army Objective Force Task Force. Home Page. 1 Apr. 2002 <http://www.objectiveforce.army.mil/oftf/pages/pao_themes_and_messages.html >.

${ }^{40}$ US Army Training and Doctrine Command. Future Operational and Threat Environment: A View of the World in 2015. By Deputy Chief of Staff for Intelligence. Fort Monroe, 2001, 3.

${ }^{41}$ Department of the Army. Army Vision. By GEN Eric K. Shinseki. Washington, DC, 1999. Oct. 1999 $<$ https://www.us.army.mil/csa/vision.html $>, 1$.

42 Department of the Army. White Paper: Concepts for the Objective Force. Washington, DC, 2001.12 Nov. 2001 <http://www.army.mil/features/WhitePaper/ObjectiveForceWhitePaper.pdf>, 10.
} 
for logistics. ${ }^{43}$ Units will still require logistic support and parallel technological advances will enable the maneuver sustainment force to sustain the Objective Force.

CSS Transformation is the overarching process that will guide required changes for Objective Force sustainment. CSS Transformation is driving a continuous transformation of Army logistics to meet future requirements. The current focus of CSS Transformation is improving the efficiencies of Army logistic systems. ${ }^{44}$ The Army is transforming from echelons of supply to a distribution-based model, trading mass for velocity. Examples of CSS Transformation include anticipatory logistics, increased velocity, total asset visibility, and improvements in information systems and communications. All of these capabilities provide sustainers improved information and situational understanding. ${ }^{45}$

Better information about supported forces can result in better support with a reduced CSS footprint, but the Army must also improve its capabilities in the physical distribution network. A significant leap forward with science and technology advances will give the Army's sustainment community the required capabilities. While Army Transformation must produce combat systems that reduce the demand for logistics, CSS Transformation must produce logistic forces capable of rapidly and continuously sustaining the Objective Force. CSS Transformation cannot occur without the expected gains from Army Transformation.

Army Transformation and CSS Transformation were previously referred to as a Revolution in Military Affairs and a Revolution in Military Logistics. In speaking of their relationship, a former Chief of Staff of the Army (CSA) said, "There will not be a Revolution in Military Affairs unless there is a Revolution in Military Logistics... You can't have a Revolution in Military Logistics

\footnotetext{
${ }^{43}$ Ibid., 9.

${ }^{44}$ United States Army Combined Arms Support Command. CASCOM After Action Report (AAR) for Army Transformation War Game 2001 (ATWG 2001). Fort Lee: CASCOM, 2001, 3.

${ }^{45}$ United States Army Combined Arms Support Command. Theater Distribution CD 111-24. CD-ROM. Fort Lee.
} 
without first changing how military forces are projected and sustained. ${ }^{\wedge 46}$ The emphasis on linking the two processes was well placed, but perhaps the emphasis was misplaced.

The Army's logistic system is a result of the requirements of sustaining Army formations based on soldiers and their weapons systems. The organizations required to provide fuel to a mechanized division are an example of this relationship. A mechanized division is supported by a division support command (DISCOM) and a corps support command COSCOM. The diagram below, from FM 63-3 Corps Support Command, illustrates the flow of fuel into a division.

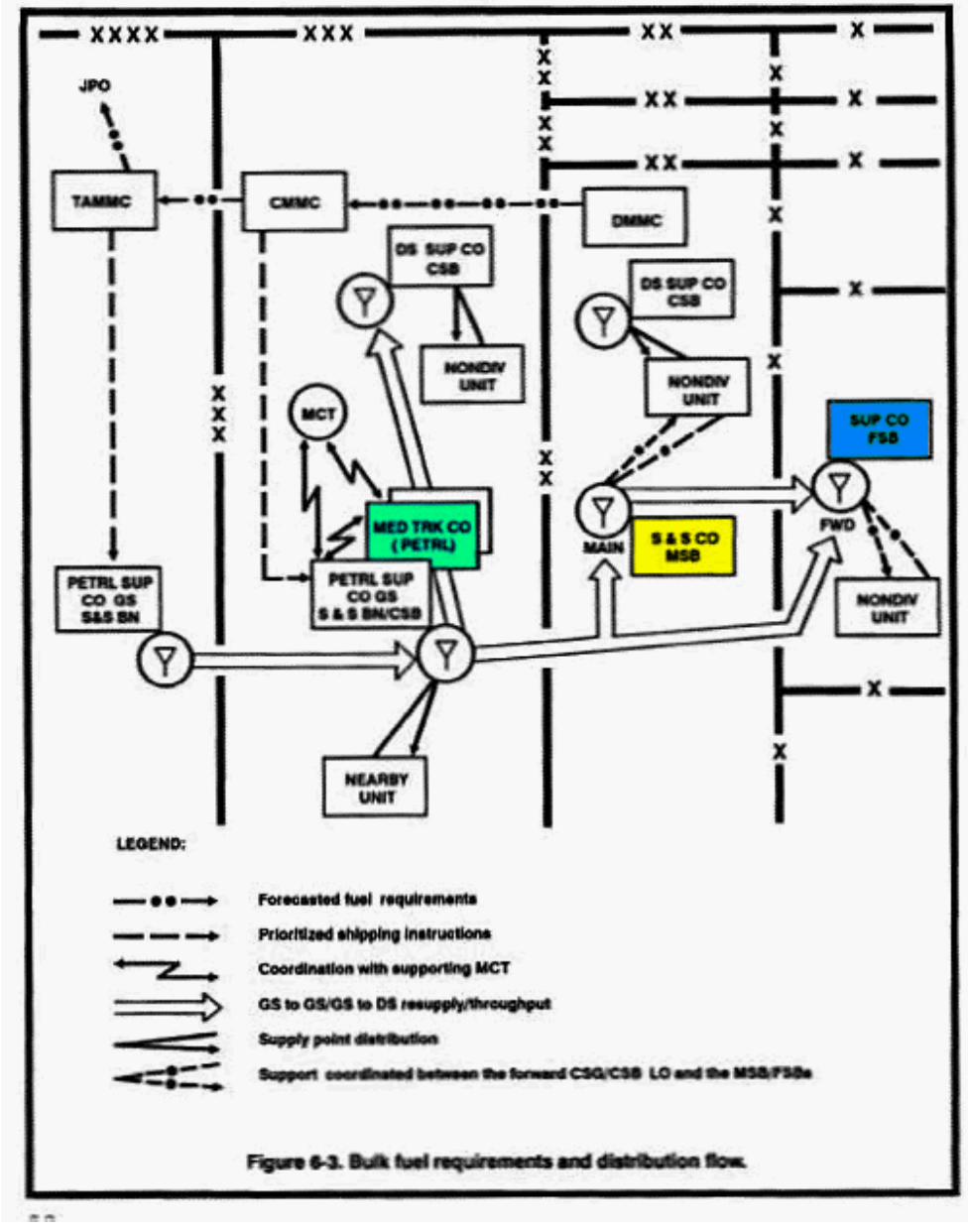

Figure 1 POL Distribution ${ }^{47}$

\footnotetext{
${ }^{46}$ Former Army Chief of Staff, General Reimer as quoted on United States Army Combined Arms Support Command. Theater Distribution CD 111-24. CD-ROM. Fort Lee.

${ }^{47}$ Source: FM 63-3, 6-8.
} 
Factors vary depending on the mission and terrain, but a mechanized division consumes approximately 542,000 gallons of fuel per day. ${ }^{48}$ If the COSCOM medium truck company (POL) (highlighted in green) is within line haul distance (90 miles) of the division, it is capable of hauling between 450,000 and 675,000 gallons of fuel per day based on equipment type and availability. ${ }^{49}$ The main support battalion (MSB) (highlighted in yellow) is capable of distributing 520,000 gallons of fuel per day if it is within local haul distance (20 miles) of the forward support battalions (FSB) (highlighted in blue).$^{50}$ The relationships between the units in terms of purpose, capabilities and distance are an example of how echelons of support were designed to meet the requirements of the supported forces.

"The kinds and amounts of CSS required in battle are directly related to the types and employment of supported forces." ${ }^{51}$ Unless there is true change in the supported force's requirements, there will never be substantive changes in the way these same forces are sustained. Army Transformation seeks a simultaneous reduction in both areas to create a more strategically deployable force. This lighter, but more capable force with reduced sustainment requirements will have greater strategic relevance by giving the US national leadership increased options. The Objective Force design characteristics encapsulate these ideas.

\section{Sustainment Imperatives}

The Objective Force White Paper outlines seven design characteristics. The Army must be responsive, deployable, agile, versatile, lethal, survivable and sustainable. These design characteristics will give the Army the required deployability and operational capabilities to accomplish its mission in the future operational environment. Given significant improvements in Air Force and Navy strategic lift, the Army will be able to put an Objective Force brigade

\footnotetext{
${ }^{48}$ United States Army Command and General Staff College. Combat Service Support Battle Book (former G1/G4 Battle Book). By Director, Department of Logistics and Resource Operations. Fort Leavenworth, 2001, 4-6.

${ }^{49}$ Ibid., 6-47.

${ }^{50}$ Ibid., 6-47
} 
anywhere in the world in 96 hours from first wheels up, a division in 120 hours and five divisions in 30 days. ${ }^{52}$ Upon arrival, the Objective Force will be prepared to conduct full spectrum operations.

Sustaining the Objective Force will require a highly capable maneuver sustainment force. The Objective Force design characteristics apply to the maneuver sustainment force and are clarified in the Army Transformation Campaign Plan (TCP) line of operation 09 (LO9), Deploying, Supporting and Sustaining the Force. ${ }^{53}$ CSS Transformation must "ensure Army forces are capable of rapidly deploying in support of current and future operational force deployment goals;" and "effectively sustain the full spectrum of Army operations." ${ }^{, 54}$ The Army G4 further states that the CSS Transformation charter is to:

- Enhance Strategic Responsiveness

- Reduce Combat Zone CS/CSS Footprint

- Reduce Cost of Logistics Without Reducing Warfighting Capability or Readiness. ${ }^{55}$

These CSS Transformation goals are interrelated. Cost reductions will be achieved by combat systems that require less maintenance and sustainment. This will result in smaller maneuver sustainment organizations with a reduced CS/CSS requirement for strategic lift, thus enhancing strategic responsiveness. Both points are related to the second item of reducing the CS/CSS footprint. The Objective Force Task Force defines it as:

\footnotetext{
${ }^{51}$ 9th Infantry Division. Motorized Experience of the 9th Infantry Division 1980-1989. Fort Lewis, 1989, 209.

${ }^{52}$ Department of the Army. White Paper: Concepts for the Objective Force. Washington, DC, 2001. 12 Nov. 2001 <http://www.army.mil/features/WhitePaper/ObjectiveForceWhitePaper.pdf>, 6. The White Paper does not explicitly mention the Air Force and Navy in the reference, but the reliance is implied.

${ }^{53}$ United States Army Deputy Chief of Staff G4, Directorate for Plans, Operations and Logistics Automation. LO9 Main: Deploying, Supporting and Sustaining the Force. 3 Mar. 2002 <http://www.hqda.army.mil/logweb/directorates/pl/Transformation\%20LO9/LO9_main.htm>.

${ }^{54}$ Charles S. Mahan, Lieutenant General "CS/CSS Transformation.” Deploying, Supporting and Sustaining the Force Web Site. 3 Apr. 2001. PowerPoint Briefing. http://www.hqda.army.mil/logweb/directorates/pl/Transformation\%20LO9/CSS\%20TRANS\%202001\%20\%203\%20APR\%2001.ppt
} 
Eliminating or reducing the physical presence of CS/CSS-oriented equipment, supplies, personnel (including contractors and civilians), and infrastructure within a given combat zone while maintaining or improving sustainment and support effects. ${ }^{56}$

Achieving these effects have implications on the Objective Force sustainment and distribution system. Maneuver sustainment forces will deploy smaller, more capable forces and support operations across greater distances. This will require capabilities that are currently immature, emerging or simply not yet possible. "The overarching goal is to provide rapid and assured sustainment to forces in full spectrum operations worldwide." ${ }^{, 57}$

\footnotetext{
${ }^{55}$ United States Army Deputy Chief of Staff G4, Directorate for Plans, Operations and Logistics Automation. LO9 Main: Deploying, Supporting and Sustaining the Force. 3 Mar. 2002 <http://www.hqda.army.mil/logweb/directorates/pl/Transformation\%20LO9/LO9_main.htm>. ${ }^{56}$ Solomon, LTG Billy K. "Reducing the Logistics Footprint in Support of the Objective Force." Presentation given at the Association of the United States Army Symposium, 8 Nov. 2001. PowerPoint Briefing

${ }^{57}$ Larry L. Harman, Colonel "Sustaining the Objective Force.” CASCOM CSS Battle Lab. 6 Aug. 2001. PowerPoint Briefing
} 


\section{CHAPTER THREE}

Today's perceptions of combat operations, widely held within the U.S. and abroad, have been filtered through the lens of Desert Storm, Bosnia and Kosovo. These perceptions include deliberate actions conducted at a tempo, which we decide, and are characterized by the application of technology and advanced systems that leave opponents virtually helpless to respond or retaliate by traditional means. These perceptions do not represent future military reality.

TRADOC, Future Operational and Threat Environment

\section{NATURE OF THE OPERATIONAL ENVIRONMENT}

It is likely that, "a geostrategic environment of considerable instability, driven by significant demographic, geopolitical, economic and technological dynamics, ${ }^{, 58}$ will characterize the next decade. The US will continue to have global interests and will remain engaged throughout the world. The strategic concepts of decisive force, power projection and overseas presence will continue to guide US force capabilities. ${ }^{59}$ The Army's part of the joint force, the Objective Force, will be "strategically responsive and dominant across the full spectrum of military operations.",60

\section{Threat Environment}

Facing future adversaries will require a full spectrum Army, capable of operating in any environment. Joint Vision 2020 describes three contributing factors to the threat environment. First, the US will continue to maintain global interests. Second, potential adversaries will have access to technology similar to that of the US. Third, potential adversaries are studying US military forces and will adapt to find ways of offsetting US advantages. ${ }^{61}$

\footnotetext{
${ }^{58}$ United States Army Training and Doctrine Command. Future Operational and Threat Environment: A View of the World in 2015. By Deputy Chief of Staff for Intelligence. Fort Monroe, 2001, 2.

${ }^{59}$ Department of Defense. Joint Vision 2020. By Chairman of the Joint Chiefs of Staff. Washington, D.C.: US Government Printing Office, 2000, 1.

${ }^{60}$ Department of the Army. Army Vision. By GEN Eric K. Shinseki. Washington, DC, 1999. Oct. 1999 https://www.us.army.mil/csa/vision.html, 1 .

${ }^{61}$ Department of Defense. Joint Vision 2020. By Chairman of the Joint Chiefs of Staff. Washington, D.C.: US Government Printing Office, 2000, 4.
} 
The US is likely to continue to dominate the world economically and militarily for the next ten years. ${ }^{62}$ US defense spending has consistently outpaced that of allies and enemies alike. Over the past decade, US defense spending has been almost twice that of its NATO allies combined. (see figure below) At the same time, US defense spending only represents about $3.0 \%$ of its GDP. In comparison against the next highest spending potential adversary, the US spent over $\$ 300$ billion in 1999 whereas China spent less than $\$ 13$ billion. ${ }^{63}$ The trend is not likely to reverse in the near term and as the US maintains its global interests; it will continue to have a significant asymmetric advantage over other military forces.

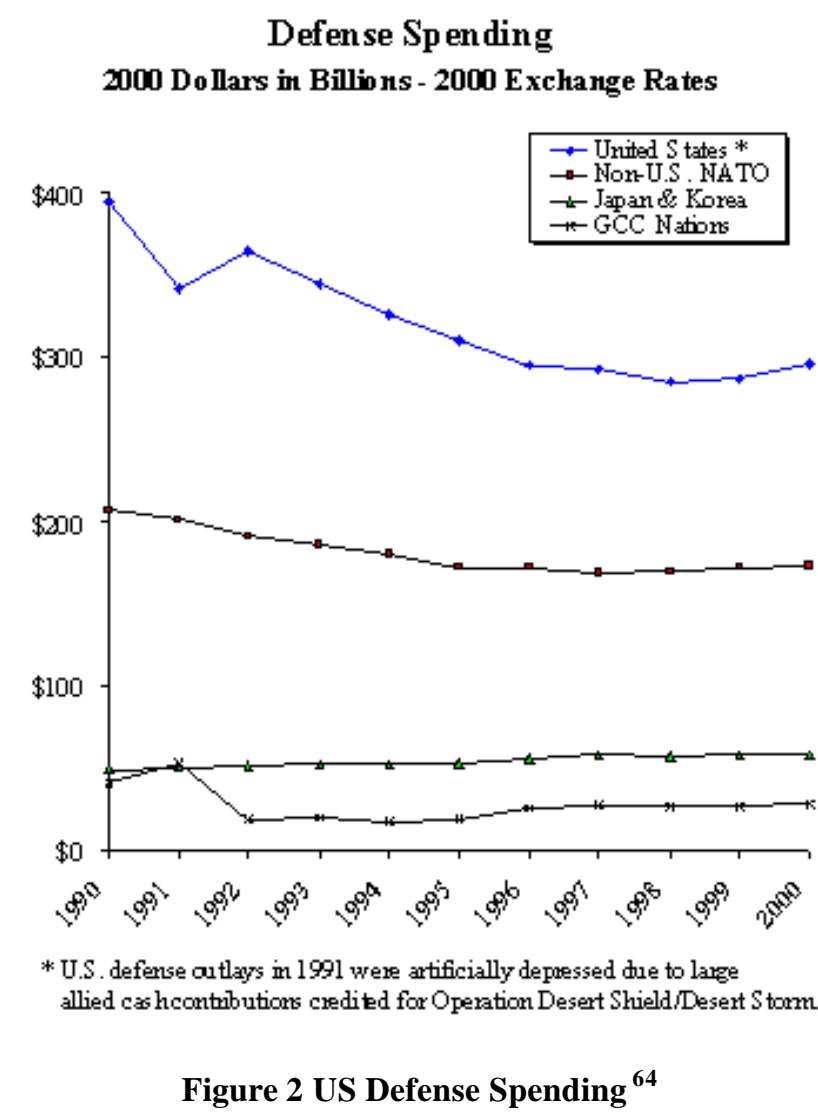

\footnotetext{
${ }^{62}$ United States Army Training and Doctrine Command. Future Operational and Threat Environment: A View of the World in 2015. By Deputy Chief of Staff for Intelligence. Fort Monroe, 2001, 3.

${ }^{63}$ Central Intelligence Agency. CIA World Fact Book. 10 Mar. 2002 $\langle$ http://www.cia.gov/cia/publications/factbook/geos/ch.html>

${ }^{64}$ Source: Department of Defense. Report on Allied Contributions to the Common Defense. By Secretary of Defense. 2001, III-4.
} 
US defense spending has created an Army that is not the largest in the world, but the most highly trained and capable. Desert Storm proved that US military forces have no peer competitors. ${ }^{65}$ The Army, enabled by US joint forces, has significant advantages in precision engagement, information and maneuver. Lacking the ability to match US military might, potential adversaries will seek ways to offset US advantages. Increasingly available information and communications may give adversaries ways of leveling the playing field. ${ }^{66}$ Technology and adversary adaptations to US forces will be another way.

New technologies will give potential foes new capabilities and old technologies applied in new ways will create other capabilities. Globalization and increased communications will make acquiring these capabilities easier and cheaper as adversaries will be able to benefit from the research and development of others. ${ }^{67}$ Opponents may leverage these means to avoid US strengths and attack perceived weaknesses.

Currently, the Army has optimized its armored and mechanized forces for fighting in Europe. These forces project power into a theater through ports of debarkation and lines of communication. The Army dominates land warfare, but its ability to project power is a potential weakness. A key tenet of Objective Force operations is the ability to build and maintain operational momentum. ${ }^{68}$ Future adversaries will attempt to control the tempo of operations by limiting or preventing the US from generating combat power. Adversary strategies will include the use of asymmetric approaches and area denial strategies. ${ }^{69}$ Their goal will be to avoid US strengths while denying the US the ability to project power and attacking perceived weaknesses. Two such perceptions of weaknesses are:

- (The) U.S. (is) unwilling to accept heavy losses and is risk adverse (sic)

\footnotetext{
${ }^{65}$ USJFCOM J9 Joint Futures Lab. Rapid Decisive Operations. 2001.

${ }^{66}$ United States Army Training and Doctrine Command. Future Operational and Threat Environment: A View of the World in 2015. By Deputy Chief of Staff for Intelligence. Fort Monroe, 2001, 7.

67 Ibid., 7.

${ }^{68}$ Department of the Army. White Paper: Concepts for the Objective Force. Washington, DC, 2001.12 Nov. 2001 <http://www.army.mil/features/WhitePaper/ObjectiveForceWhitePaper.pdf>, 4.
} 
- The US will rely on air campaigns and standoff technology ${ }^{70}$

Specific methods of attack will vary by region and type of threat. This will create diverse risks to Army operations. The intent will be to create maximum US casualties and negate the effects of standoff technology. These factors will cause adversaries to try to fight on terms favorable to their method of operation and unfavorable to the US. Enemies will try to create problems for both Army maneuver and maneuver sustainment forces.

Adversaries may move into complex and urban terrain to try to diminish the value of standoff weapons and Army maneuver. The Army must be capable of fighting anywhere, but some enemies will have the advantage of organizing to fight in a particular environment. ${ }^{71}$ These physical environments will not only define the fight, but also define how the fight is supported. The maneuver sustainment system will have to overcome these environmental challenges.

Maneuver sustainers will support increasingly dispersed maneuver forces, fighting in complex and urban terrain; with an adversary focused on inflicting US casualties. Movement through this environment will be difficult, as maneuver sustainment forces may become likely targets of future adversaries. Attacking the sustainment system may prove more lucrative because the benefit could be a disruption in US combat power as well as to achieve casualties. Objective Force maneuver sustainment organizations will have to develop counter adaptations to threat efforts to operate in a full spectrum environment.

Current doctrine for protection of logistic assets is a system of escalating defensive responses categorized as levels 1-3. This system requires mutually supporting logistic bases augmented with military police and a tactical combat force based on linear battlefield geometry. Logistic units gain protection from the bases and the combat forces forward of their positions. ${ }^{72}$

\footnotetext{
${ }^{69}$ USJFCOM J9 Joint Futures Lab. Rapid Decisive Operations. 2001, 3.

${ }^{70}$ United States Army Training and Doctrine Command. Future Operational and Threat Environment: A View of the World in 2015. By Deputy Chief of Staff for Intelligence. Fort Monroe, 2001, Appendix A. ${ }^{71}$ Ibid., 7-8.

72 Department of the Army. Field Manual 63-3 Corps Support Command. Washington, DC, 1993 Chapter 11.
} 
This system is not well suited for protection of maneuver sustainment assets in the Objective Force era. Two of the elements that logistic units gained protection from, a linear battlefield and mutually supporting logistics base, will not be common in the future operational environment. Lacking these protection enablers, Army sustainment organizations may become more vulnerable. As adversaries adopt an indirect approach to defeating Army forces, maneuver sustainment forces will be one of their targets. ${ }^{73}$

Part of the maneuver sustainment vulnerability results from the Army's primary transportation mode, the truck. "Motor transport is the backbone of the Army's support and sustainment structure. ${ }^{, 74}$ Army trucks, in conjunction with host nation and allied assets, haul the majority of the materiel required for combat. Unless the Army develops a credible alternate mode for overland transport, trucks will continue to be the workhorse of the future. Trucks represent a vulnerability because of their design features.

Most Army sustainment vehicles have soft skins and limited weapons capability. Many of the Army's prime movers in a theater of operations require improved roads. Patterns of movement along these roads will create a one-dimensional approach to maneuver sustainment and a predictability that future enemies can exploit. TP 525-3-0 states "one-dimensional operations in effect simplify an enemy's war fighting problem, confronting him with a finite threat against which he can concentrate his own efforts confident that he will not be surprised." ${ }^{\text {75 }}$ This refers to confronting enemies with multi-dimensional threats, but it can also apply to presenting the enemy with multiple dilemmas in trying to disrupt the Army's sustainment system.

The Army's over-reliance on motor transport operations for logistics can create a onedimensional opportunity for future adversaries. Unable to defeat an Objective Force maneuver

\footnotetext{
${ }^{73}$ United States Army Training and Doctrine Command. Future Operational and Threat Environment: A View of the World in 2015. By Deputy Chief of Staff for Intelligence. Fort Monroe, 2001, 8-9.

${ }^{74}$ Department of the Army. Field Manual 55-15 Transportation Reference Data. Washington, DC, 1997, 31.

${ }^{75}$ United States Army Training and Doctrine Command. TRADOC Pamphlet 525-3-0, The United States Army Objective Force Operational and Organizational Concept (Draft 11 Nov 01). Fort Monroe, 2001, 10.
} 
formation, a future adversary may seek to isolate the unit by denying its logistics. An Objective Force unit may have three to seven days of endurance, but certain terrain may enable adversaries to block ground lines of communication for extended periods of time. Unless the Army has credible alternative transportation modes and new methods of providing protection, the maneuver sustainment system will be vulnerable to attack.

\section{Friendly Forces}

Doctrine for employment of the Objective Force is developing. Units will be organized into units of employment and units of action. Units of employment (UE) will serve similar functions to corps and divisions. Units of action will function at the brigade and battalion level. The UE/UA concept is the basis by which the Objective Force will be employed in a theater of operations.

Units of Employment are the basis of combined arms air-ground task forces. They resource and execute combat operations; designate objectives; coordinate with multi-service, interagency, multinational and non-governmental activities; and employ long range fires, aviation and sustainment. They also provide C4ISR and tactical direction to UAs. ${ }^{76}$

Units of Employment will be the higher level operational and tactical commands. They will integrate and synchronize the operations of Army, joint and multinational forces and be responsible for sustained campaigns. They will prosecute these campaigns using patterns of operation. $^{77}$

The Unit of Employment patterns of operation include: force projection, entry and shaping operations, decisive operations, information superiority, force protection, sustainment and transition. Force projection may involve operational maneuver from a strategic distance and include a forced entry. Units of Employment will direct continuous sustaining and shaping operations to prepare for decisive operations. Leadership and advanced technologies will give the

\footnotetext{
${ }^{76}$ Department of the Army. White Paper: Concepts for the Objective Force. Washington, DC, 2001. 12 Nov. 2001 <http://www.army.mil/features/WhitePaper/ObjectiveForceWhitePaper.pdf>, 11.

${ }^{77}$ United States Army Training and Doctrine Command. Objective Force Unit of Employment Draft Concept. By Joint and Army Concepts Directorate Deputy Chief of Staff for Doctrine. 15 Aug 2001. PowerPoint Briefing
} 
Unit of Employment the capability to gain information superiority and protect the force. Units of Employment will direct Units of Action for decisive operations. ${ }^{78}$

Both Units of Employment and Units of Action will have associated maneuver sustainment units. Sustainment organizations associated with Units of Action will probably be organic. Sustainment organizations associated with Units of Employment will either be organic or habitually supported. Units of Action will be replenished by the higher supporting organization on an as-needed basis; the goal being every three to seven days.

Units of Action will be the tactical fighting elements of the Objective Force. ${ }^{79}$ Although force developers show Units of Action as brigades and battalions, their formations may look significantly different than today's. Units of Action will be capable of combined arms operations at lower levels and be able to transition quickly between operations at a high tempo. Many enabling technologies will give Units of Action these capabilities. The centerpiece of its technologies will be the Future Combat System (FCS).

The FCS will be the primary US Army weapon system of the Units of Action. ${ }^{80}$ The Army has not yet to developed this system, but based on current design parameters, it will weigh about 20 tons, require some type of fuel and have a projectile weapon. The FCS will also make potable water for the crew. Compared to today's main battle tank, the M1 Abrams, it will require much fewer consumable materials. Instead of requiring fuel daily, it will require fuel every three to seven days depending on the operation. The projectiles will weigh much less than current tank rounds.

The FCS will be capable of rapid maneuver at extended tactical distances. This will relieve commanders of many of the current logistic challenges faced by heavy and mechanized forces

\footnotetext{
78 Ibid.

79 Department of the Army. White Paper: Concepts for the Objective Force. Washington, DC, 2001. 12 Nov. 2001 <http://www.army.mil/features/WhitePaper/ObjectiveForceWhitePaper.pdf>, 11.

${ }^{80}$ United States Army Training and Doctrine Command. Objective Force Unit of Employment Draft Concept. By Joint and Army Concepts Directorate Deputy Chief of Staff for Doctrine. 15 Aug 2001. PowerPoint Briefing
} 
today, but it will create new challenges. Like any system, the FCS will eventually need additional fuel, projectiles or repair parts. This could be problematic for the Objective Force maneuver sustainer because FCS equipped units will be more dispersed and further away from sustainment bases.

The key will be to establish reliable, flexible and high capacity distribution networks within the theater to support FCS equipped units. This reliance on the distribution network will require that Objective Force maneuver sustainment units have the capability to rapidly move men and materiel throughout an area of operations via extended lines of communication.

\section{Decisive Operations Zones and White Space}

Units of Employment will designate areas to conduct decisive operations called decisive operations zones. Units of Action will conduct decisive operations in the decisive operations zone. The decisive operations zone will be, "the area in which the combat battalion concentrates its combat power to produce overmatching effects at the decisive time and place to defeat the enemy and accomplish its mission." ${ }^{81}$ A three to seven day operational range and the ability to master transitions will give Units of Action the capability to attack multiple decisive operations zones throughout the battle space.

The area in between decisive operations zones is called white space. Units of Action will link up with maneuver sustainment units in the white space to conduct sustainment operations. The white space will be inherently unsecured unless occupied by friendly forces. Maneuver sustainment units will pulse logistic support to maneuver units as required. Potential adversaries will seek to disrupt friendly operations in the white space. Maneuver sustainment organizations must be capable of operating in the white space to accomplish their mission.

The relationship between decisive operations zones and white space provide the operational framework for Objective Force sustainment operations. Maneuver units will be capable of 
extended maneuvers to attack decisive operations zones. Objective Force units will have greater endurance and require less sustainment, but will be widely dispersed. Maneuver sustainment units must have sufficient reach to sustain the Objective Force, but reach is limited by its primary transportation mode, the truck. As the Army executes its transformation, new and better capable transportation modes may be required to sustain the Objective Force.

${ }^{81}$ United States Army Training and Doctrine Command. TRADOC Pamphlet 525-3-90, The United States Army Objective Force Tactical Operational and Organizational Concept for Maneuver Units of Action (Draft 7 Nov 01). Fort Monroe, 2001. 


\section{CHAPTER FOUR}

Regardless of future challenges, the overarching goal of maneuver sustainment must be: rapid and assured provisioning of sustainment to forces worldwide across the full spectrum of military operations, thus guaranteeing the ability to build, generate, and maintain overmatching combat power at the point(s) of decision as determined by the commander(s) on the ground.

$\underline{\text { TRADOC PAM 525-4-0, Objective Force Maneuver Sustainment }}$

\section{OBJECTIVE FORCE SUSTAINMENT}

The purpose of the Objective Force sustainment concept is to sustain the maneuver commander in full spectrum operations. This concept derives from Joint Vision 2020 the Army Vision, Army Transformation Campaign Plan and CSS Transformation. CSS Transformation is a broad and all encompassing concept that involves all aspects of transforming Army logistics to Objective Force maneuver sustainment.

There are many characteristics to CSS Transformation, but there are three broad areas addressed in the Objective Force sustainment concept: people, information and capabilities. Soldiers will be the centerpiece of the Objective Force sustainment concept. Sustainment warriors will be enabled by information technologies that give them the capability to know and anticipate the needs of supported maneuver commanders. This will create unprecedented situational understanding when combined with an ability to see and understand the battlefield. Emerging capabilities will give them the ability to translate requirements into distribution of required sustainment.

These capabilities will not only allow delivery of supplies from a sustainment base to a unit, but the ability to do it in any environment. Future battlefields may be linear or noncontiguous. Vertical envelopment, speed and high operational tempo will be key aspects of Objective Force

operations. ${ }^{82}$ These expected battlefield characteristics will not allow time for significant sustainment build up and will extend lines of communication between Objective Force maneuver 
and sustainment units. Extended lines of communication will create white space in the battlefield that will not be secure at all times. Maneuver sustainment and distribution will overcome time and distance to provide focused logistics, but have resilience to enemy interdiction. It will be responsive, multi-modal, and have sufficient velocity to maintain maneuver operational momentum. ${ }^{83}$

\section{Redefining Logistic Concepts}

As the Objective Force concept matures the concepts of tactical and operational logistics will be redefined. The tactical level of logistics was associated with the retail level, which was the point where logistic units directly provided support to maneuver units. Operational level logistics was concerned with preparing for major operations. These concepts applied to legacy forces operating on a linear battlefield with multiple echelons of support. The Objective Force sustainment concept introduces four new concepts: warrior sustainment, unit sustainment, mission staging and sustainment replenishment.

Warrior sustainment will be sustainment embedded into the maneuver platforms. The FCS' ability to make water for the crew is an example. Warrior sustainment will increase Objective Force endurance and help to reduce the logistic footprint by reducing or eliminating the need to distribute some supplies. Unit sustainment will focus "on those functions, which cannot be embedded into the warrior system, and must be distributed or provided in the battlespace., $\$ 4$ Sustainment units will have to maneuver to link up with maneuver units to conduct unit sustainment operations.

\footnotetext{
${ }^{82}$ Department of the Army. White Paper: Concepts for the Objective Force. Washington, DC, 2001. 12 Nov. 2001 <http://www.army.mil/features/WhitePaper/ObjectiveForceWhitePaper.pdf>, 7-8.

${ }^{83}$ United States Army Training and Doctrine Command. TRADOC Pamphlet 525-4-0, The United States Army Objective Force Maneuver Sustainment Operational and Organizational (O\&O) Concept (Draft 11 Feb 2002). By CASCOM CSS Battle Lab. Fort Monroe, 2002, 5-6.

${ }^{84}$ Ibid., 25.
} 
Mission staging will be a unit sustainment operation that is intense, time-sensitive and "includes all preparations for an upcoming mission." ${ }^{, 5}$ It will be a deliberate operation designed to support transitions to other missions. Sustainment replenishment will be "a quick, in-stride, sustainment operation that fits within the battle rhythm" and is designed to support ongoing missions. ${ }^{86}$ The operational goal is to pulse the required type of sustainment once every three to seven days or on an as-needed basis to mission staging sites. A mission staging site will be a predetermined site in the battle space where mission staging or replenishment operations will occur.

\section{Objective Force Environment}

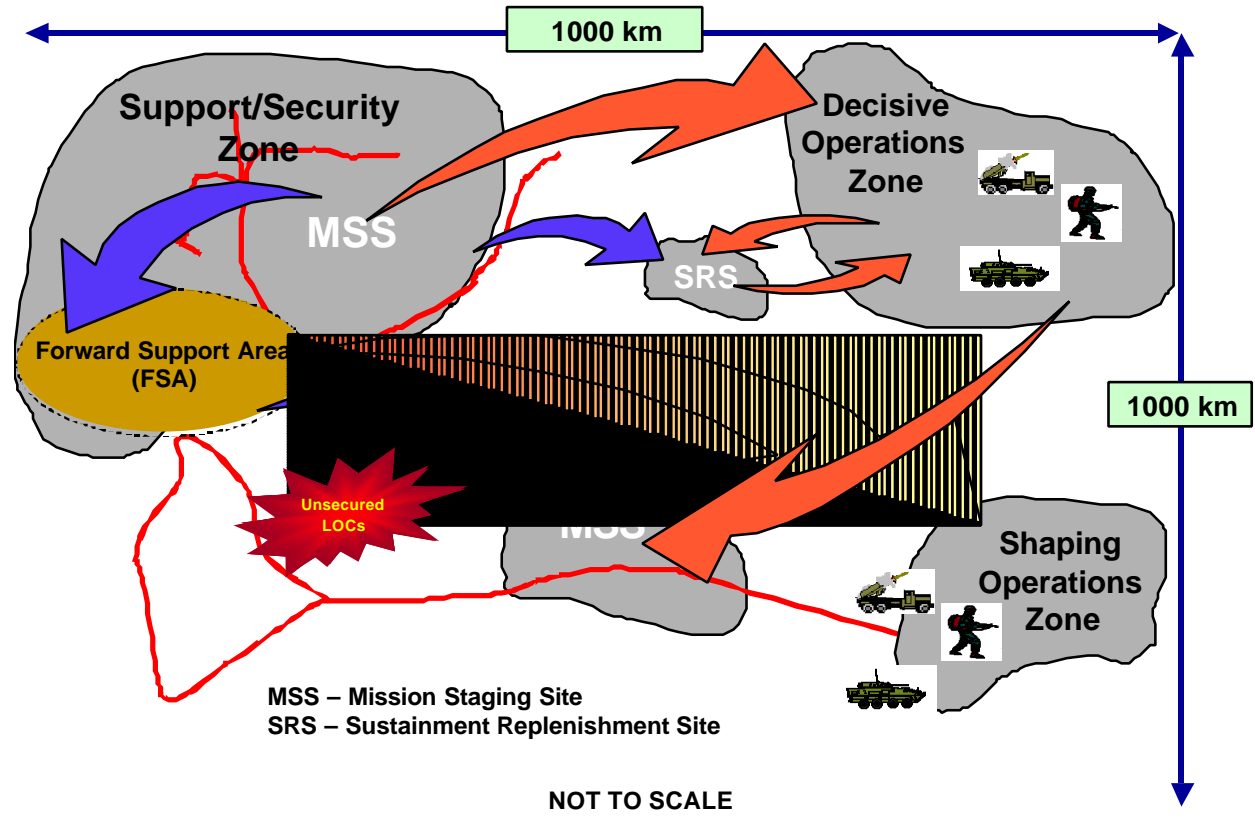

Figure 3 Corps Objective Force Environment ${ }^{87}$

The operational distances over which these operations will occur will necessitate a reliance on aerial transportation modes. The Objective Force will maneuver from strategic distances and initiate operations without established infrastructure in the theater. Ground lines of

\footnotetext{
85 Ibid., 21.

86 Ibid., 21.

${ }^{87}$ Source: Modified PowerPoint slide from Larry L. Harman, Colonel "Sustaining the Objective Force." CASCOM CSS Battle Lab. 6 Aug. 2001. PowerPoint Briefing
} 
communication may be available as the theater develops, but there will still be a heavy reliance on aerial sustainment. These insights are the result of a variety of works used to develop the Objective Force sustainment concept.

\section{Insights from Previous Works}

The need to fuse airpower and land power was an insight from an Army After Next (AAN) Tactical War Game (TWG) in the late 1990s. Most examples cited dealt with the USAF air combat role, but two air mobility issues were addressed. The first was the requirement to conduct 300-500 kilometer vertical maneuvers via intra-theater airlift. ${ }^{88}$ The other was that friendly forces' operational reach was inhibited by the distance to the support base and a lack of lift aircraft. ${ }^{89}$ These key points were revisited during the Army Transformation War Game 2001 (ATWG 2001).

The requirement for intra-theater airlift was validated throughout ATWG 2001. Intra-theater air transportation was cited as a necessity to facilitate maneuver. ${ }^{90}$ The Objective Force also created a significant demand for intra-theater supply distribution by air. ${ }^{91}$ Although ATWG 2001 CSS participants validated the requirement for aerial sustainment, they made operational assumptions on the availability of aircraft that do not yet exist. ${ }^{92}$ Once these capabilities were assumed, the benefits of aerial sustainment to the Objective Force were apparent.

\section{Benefits and Challenges to Aerial Sustainment}

The benefits of aerial sustainment to the Objective Force are clearly understood. It will increase sustainment reach and provide a more assured means of providing time definite delivery. An aerial-based sustainment system will traverse man made and natural obstacles and provide a

\footnotetext{
${ }^{88}$ Echevarria II, Antulio J. "Fusing Airpower and Land Power in the Twenty-First Century: Insights from the Army after Next." Aerospace Power Journal Fall 1999. 1 Apr. 2002 <http://www.airpower.maxwell.af.mil/airchronicles/apj/apj99/fal99/echevar.html>, 5.

${ }^{89}$ Ibid., 6.

${ }^{90}$ United States Army Combined Arms Support Command. CASCOM After Action Report (AAR) for Army Transformation War Game 2001 (ATWG 2001). Fort Lee: CASCOM, 2001, 18.

${ }^{91}$ Ibid., 6.

92 Ibid., 2.
} 
rapid distribution capability. Advanced aerial platforms will also enhance operational agility as they can be used to bypass ports of debarkation and reposition forces throughout the battlefield. They will also allow the Army to utilize the third dimension and not rely solely on ground lines of communication. Though there are many benefits, there are also significant challenges to developing an aerial based sustainment and distribution system.

The primary challenge is the distribution capacity provided by available and projected aerial platforms. Current Army aviation logistic doctrine recognizes the mission to provide operational level airlift with corps level $\mathrm{CH}-47$ helicopters, but that aerial movement of heavy supplies is relatively inefficient. ${ }^{93} \mathrm{C}-130$ and $\mathrm{C} 17$ aircraft are the primary joint assets, however the Mobility Requirements Study 05 assessed shortfalls with these aircraft in providing intra-theater airlift. ${ }^{94}$ Other challenges to aerial sustainment are a result of the operational environment.

Aircraft are inherently susceptible to adverse weather and decreased lift capability depending on atmospheric conditions. ${ }^{95}$ Dedicated aerial sustainment vehicles will require organic airspace command and control capability within sustainment organizations to effectively employ the distribution system and prevent airspace conflicts. Suppression of enemy air defenses (SEAD) and the capability to conduct combat search and rescue (CSAR) will also be required. Increasing the number of airframes will require an increase in the infrastructure required to maintain them. Furthermore, ATWG 2001 found that fuel usage actually spiked when intra-theater aircraft were heavily used. ${ }^{96}$ These challenges will have to be overcome in order to successfully implement an aerial-based sustainment and distribution system.

\footnotetext{
93 Department of the Army. Field Manual 1-100 Army Aviation Operations. Washington, DC, 1997, 1-10.

${ }^{94}$ United States Transportation Command. Mobility Requirements Study 05. 2001. 5.

95 Department of the Army. Field Manual 55-15 Transportation Reference Data. Washington, DC, $1997,2-$ 2.

${ }^{96}$ United States Army Combined Arms Support Command. CASCOM After Action Report (AAR) for Army Transformation War Game 2001 (ATWG 2001). Fort Lee: CASCOM, 2001, 19.
} 


\section{Historical Aerial Sustainment Efforts}

The Army's attempts to use aerial platforms for sustainment date back to the interwar period after World War I (WWI). Each effort addressed an operational requirement, but plans were never fully developed and implemented. In 1923, Lieutenant Colonel Ira F. Fravel, of the Army Air Service, wrote an article in the Quartermaster Journal that envisioned a day when the skies would be used as highways. The concept was based on using lighter than air airships similar to German designs. ${ }^{97}$ The author addressed many of the issues facing Objective Force developers today.

Lieutenant Colonel Fravel noted that his airship concept could have deployed to France faster and with less cargo handling than marine craft. ${ }^{98}$ This is similar to modern concepts of strategic responsiveness and strategic packaging. He also pointed out airship advantages such as the ability to overcome obstacles and a lack of reliance on theater infrastructure such as roads and airfields. Lieutenant Colonel Fravel even suggested using the convoy system as a way of defeating enemy attempts at interdiction with airplanes. ${ }^{99}$ Despite his vision, the aerial-based system was never adopted by the US Army. The US civilian market for lighter-than-air airships never developed and military uses in coming decades were limited.

Between 1951 and 1953, the Armored School at Fort Knox, Kentucky conducted two studies: Aerial Resupply of the Armored Division (1951-1952) and Air Resupply of Armored Units (1952-1953). The problem that the first study sought to remedy was to, "determine the application of aerial resupply and the role cargo aircraft might play in influencing operations of an armored division under conditions of rapid offensive movement and extended distances." ${ }^{\text {"100 }}$ The goal was to retain the flexible characteristics of the armored division given the constraints imposed by the

\footnotetext{
${ }^{97}$ Fravel, LTC Ira F. “Freight Above the Clouds.” Editorial. Quartermaster Journal June 1924: 29.

98 Ibid.: 29.

99 Ibid.: 30 .

${ }^{100}$ Department of the Army. Aerial Resupply of the Armored Division. By Roy Moore, et al. Fort Knox: Armored School, 1952,4.
} 
logistic system. ${ }^{101}$ The study considered designing logistic forces to be more mobile and redesigning armored forces to be lighter. Neither was deemed practical, especially combat system redesign that was characterized as "out of the question." 102

Aerial Resupply of the Armored Division examined the use of cargo aircraft: USAF cargo planes and US Army helicopters. Cargo aircraft provided greater logistic speed, mobility and independence from a road network. ${ }^{103}$ The study simulated an armored division in an offensive scenario to determine the requirements. Findings concluded that aerial resupply could greatly facilitate armored division operations, but ground transportation was still required because of the heavy and medium tanks. Furthermore, significant numbers of cargo aircraft were required to support the operation. ${ }^{104}$

At D+1, 228 Army helicopters were required. USAF cargo plane requirements peaked at 214 during D+2. ${ }^{105}$ Neither aircraft, however, possessed the necessary characteristics to supply the armored division. ${ }^{106}$ Helicopters could land almost anywhere, but lacked lift capacity. Cargo airplanes had greater capacity, but would have caused the armored division to make airfields intermediate objectives to facilitate loading and unloading of cargo. Even if the Army and Air Force were able to surge to meet those requirements, it seems impractical that such a system could ever have been implemented. The writers recommended further research and experimentation and the Armored School published another study a year later.

In the 1953 study, Air Resupply of Armored Units, the Armored School sought to develop a "workable system of aerial resupply for armored units." 107 This was a less ambitious effort to give the armor community a way to maneuver without the constraints of logistics. The study's

\footnotetext{
101 Ibid., 3.

102 Ibid., 3.

103 Ibid., 4.

104 Ibid., 57.

105 Ibid., 51

106 Ibid., 58.

${ }^{107}$ Department of the Army. Air Resupply of Armored Units. By MAJ John T. Pierce III, et al. Fort Knox: Armored School, 1953, 1.
} 
methodology involved development of preplanned logistics packages named, "On-Call Packets" that could be rapidly delivered by aircraft. As such, the writers identified three problems:

1. What should be in the packets?

2. What special training would armored forces require to implement the system?

3. What would be the best method of delivery? ${ }^{108}$

The focus of the study was on the first two questions. The Army wanted to determine what it could do to facilitate aerial sustainment by training, organization and packaging initiatives. The study did not attempt to answer the third question. Neither study succeeded in producing a workable solution to the problem of supporting an armored force in depth on the offensive. The Army was unwilling to seriously consider redesigning combat systems to reduce demand and it put unrealistic expectations on an aerial sustainment system.

During the early 1950s, the Army also began to develop its airmobile concept. The genesis of Army air mobility developed within the framework of the nuclear battlefield in Europe. ${ }^{109}$ The first use of airmobile units on a battlefield came in Vietnam, over a decade later. These were light units designed to have great mobility and firepower. ${ }^{110}$ Although Vietnam is an historical example of the extensive use of Army air mobility in combat, it does not parallel the expected Objective Force environment or patterns of operation.

The Vietnam War was unconventional in the sense that the battlefield did not have a linear array and operations were carried out from base camps dispersed throughout the battlefield. ${ }^{11}$ The early years of the deployment and build up were spent building the infrastructure and logistic system. The logistic system in Vietnam was rooted in the base camps and the operational reach of

\footnotetext{
108 Ibid., 1.

109 Andrew F. Krepinevich, The Army and Vietnam. Baltimore: The Johns Hopkins University Press, 1986, 112.

${ }^{110}$ Ibid., 120-121

111 Julian F. Thompson, Lifeblood of War: Logistics in Armed Conflict. London: Brassey’s, 1991, 193.
} 
combat units was tied to their proximity to these camps. ${ }^{112}$ The camps were in the combat zone and required resources to defend.

Although the expected Objective Force environment seems to have some similarities to the Vietnam War, from a logistic perspective, it is quite different. The nonlinear battlefield, dispersed objective areas and use of airmobile forces are similar. However, the lengthy logistic build up, multiple bases in the combat zone and limited reach of the forces is dissimilar and unacceptable for the Objective Force. Aerial sustainment was frequently used in Vietnam, but the supported forces were often light or had limited range objectives. Army Transformation and the Objective Force are the Army's first real attempt at addressing drastic demand reductions that could make aerial sustainment a possibility for a futuristic mounted force with extended reach.

${ }^{112}$ Ibid., 199 


\section{CHAPTER FIVE}

\section{ASSESSMENT}

The purpose of this monograph is to determine if the Army can successfully execute its Objective Force transformation without an aerial based sustainment and distribution system at the operational level. To answer this question, it is important to understand the alternatives. Currently the Army has a surface based sustainment and distribution system because it relies primarily on motor transport. An aerial based system means that the Army would primarily sustain Objective Force units by air, but would not eliminate surface based transportation modes. The result would be a net gain in the Army's aerial transportation assets and overall lift capabilities. The following assumptions form the basis for comparison.

\section{Assumptions}

Regardless of how low Objective Force consumption rates are, a sustainment base will exist within some proximity to the area of operations to allow replenishment of the forces. The Objective Force will have a reduced CS/CSS footprint in the battle space and primarily rely on a distribution based sustainment system. This system will have multiple modes and nodes and the Army will continue to use trucks, aerial vehicles and intermodal transfer points.

A surface based sustainment system will launch missions from a support base and operate along roads, rail, inland waterways and pipelines. For the purpose of comparison, rail, inland waterways and pipelines will be omitted because of a lack of universal availability. Motor transport can be made available anywhere the Objective Force operates because there will be significant advances in truck technology. Future trucks will have high mobility and an improved capability to avoid both natural and man made obstacles. However, terrain such as bridges and waterways will continue to constrain motor transport operations. Human operator endurance will also limit motor transport operations even though there will be some unmanned trucks. 
An aerial-based sustainment system will have a support base from which to launch and recover and will operate along air lines of communication. Even with advances in aviation technology, aerial vehicles will have less capacity than trucks. Future aerial vehicles will be able to operate in zero visibility, but still remain susceptible to severe weather and environmental conditions such as storms and variations in altitude. The operating radius of the aerial vehicles and the physical endurance of the operators will constrain the reach of the system. Human operators will fly the majority of the aerial sustainment vehicles, but there will be unmanned versions as well.

The operational environment will not allow entry through ports of debarkation, will have limited external support available and unsecured lines of communication. The Objective Force will conduct operational maneuver from strategic distances and arrive in the area of operations ready to fight. During sustained operations, Objective Force units will operate for three to seven days without external replenishment. The following scenario provides the context for evaluation.

\section{Objective Force Sustainment Example}

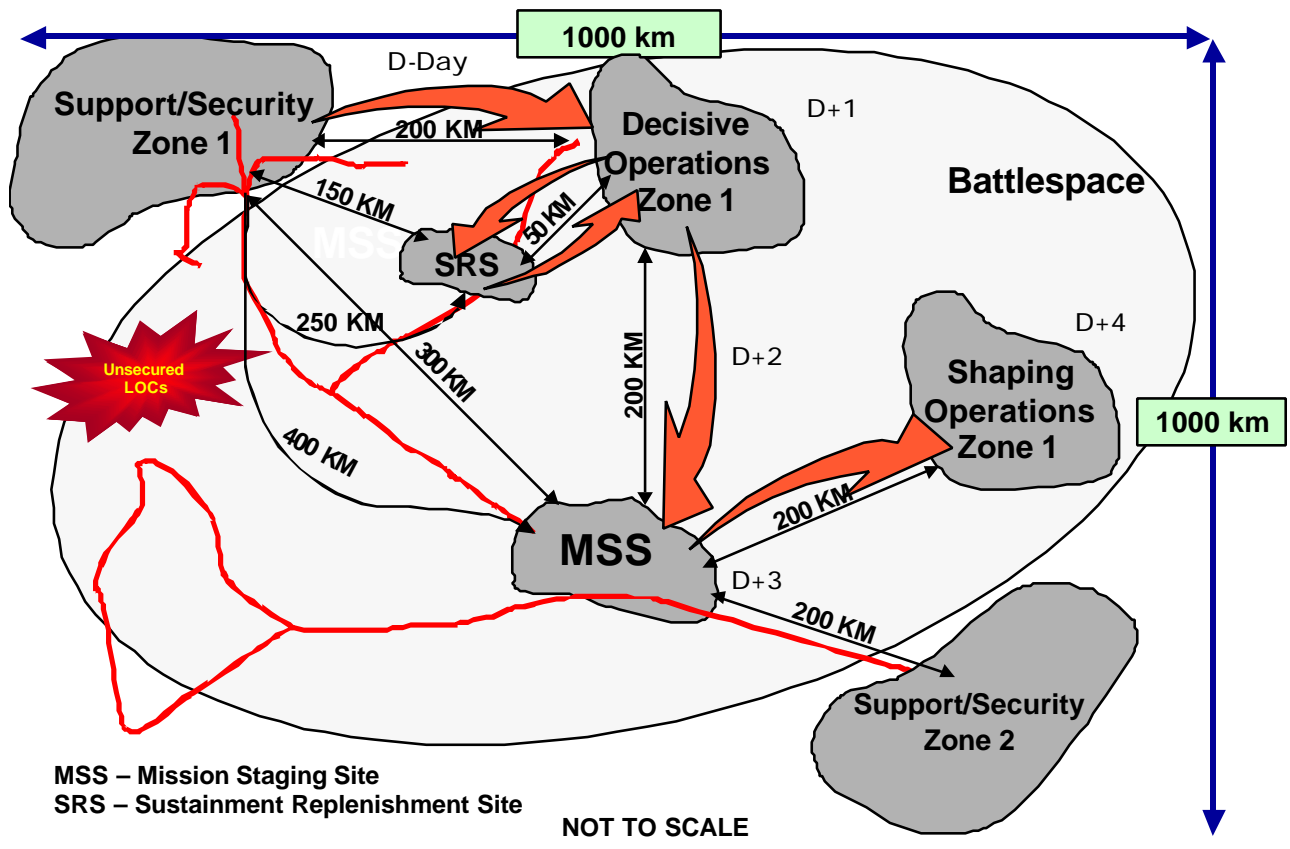

Figure 4 Hypothetical Objective Force Sustainment 
The year is 2015 and this hypothetical Objective Force operation begins after the arrival of a Unit of Action and a support force in theater in the support/security zone. A division air-ground task force employs the Unit of Action synchronized with concurrent operations elsewhere in the theater. The Unit of Action's missions consist of decisive operations followed by shaping operations. Sustaining operations include sustainment replenishment and mission staging. The shaded and curved arrows in the illustration above indicate the Unit of Action's lines of operation while conducting its missions. The area inside the large oval represents the battle space. The Unit of Action conducts its missions on the ground, but the support force can sustain by air or surface.

On D-day, the Unit of Action arrives in theater and maneuvers for 200-kilometers to its first objective, Decisive Operations Zone 1. Combat is at high intensity and the Unit of Action can sustain itself for three days. ${ }^{113}$ On D+1 the Unit of Action conducts decisive operations and consumes its second day's sustainment. During the fight, it cycles its subordinate units through the Sustainment Replenishment Site (SRS) established by the support force on D+1. On D+2, decisive operations are complete and the Unit of Action maneuvers to the Mission Staging Site (MSS). The Unit of Action conducts MSS operations on D+3 to transition to shaping operations that will occur on $\mathrm{D}+4$.

The Unit of Action is equipped with FCS and the support force has future trucks and aerial vehicles. Both the FCS and future truck systems will have an operational ground speed of 50 kilometers per hour. Aerial sustainment vehicles have an average air speed of 300 kilometers per hour. Operations in the SRS will take six hours and MSS operations will take twelve hours including preparation time. The total time the sustainment force spends in the battle space will vary depending on how far the SRS or MSS is from the support/security zone. The transportation

\footnotetext{
113 Objective Force documents presuppose that a Unit of Action can operate for three days in a high intensity environment without replenishment from external sources. Logic dictates that during high intensity operations, the Unit of Action will conduct its first external sustainment operation prior to the end of the third day. Subsequent external sustainment operations can occur every following third day.
} 
mode will determine duration of travel both to and from the sites. The table below lists travel times by mode between significant terrain in the scenario.

\begin{tabular}{|l|l|l|l|l|l|l|}
\hline Unit & From & To & Distance & Terrain & Mode & $\begin{array}{l}\text { Travel } \\
\text { Time }\end{array}$ \\
\hline $\begin{array}{l}\text { Unit of } \\
\text { Action }\end{array}$ & $\begin{array}{l}\text { Support } \\
\text { Zone }\end{array}$ & $\begin{array}{l}\text { Decisive } \\
\text { Ops Zone }\end{array}$ & $200 \mathrm{KM}$ & $\begin{array}{l}\text { Cross } \\
\text { Country }\end{array}$ & FCS & 4 hours \\
\hline $\begin{array}{l}\text { Unit of } \\
\text { Action }\end{array}$ & $\begin{array}{l}\text { Decisive } \\
\text { Ops Zone }\end{array}$ & SRS & $50 \mathrm{KM}$ & $\begin{array}{l}\text { Cross } \\
\text { Country }\end{array}$ & FCS & 1 hour \\
\hline $\begin{array}{l}\text { Unit of } \\
\text { Action }\end{array}$ & $\begin{array}{l}\text { Decisive } \\
\text { Ops Zone }\end{array}$ & MSS & $200 \mathrm{KM}$ & $\begin{array}{l}\text { Cross } \\
\text { Country }\end{array}$ & FCS & 4 hours \\
\hline $\begin{array}{l}\text { Unit of } \\
\text { Action }\end{array}$ & MSS & $\begin{array}{l}\text { Shaping } \\
\text { Ops Zone }\end{array}$ & $200 \mathrm{KM}$ & $\begin{array}{l}\text { Cross } \\
\text { Country }\end{array}$ & FCS & 4 hours \\
\hline $\begin{array}{l}\text { Sustainment } \\
\text { Force }\end{array}$ & $\begin{array}{l}\text { Support } \\
\text { Zone }\end{array}$ & SRS & $150 \mathrm{KM}$ & Air LOC & $\begin{array}{l}\text { Aerial } \\
\text { Vehicle }\end{array}$ & 30 minutes \\
\hline $\begin{array}{l}\text { Sustainment } \\
\text { Force }\end{array}$ & $\begin{array}{l}\text { Support } \\
\text { Zone }\end{array}$ & SRS & $250 \mathrm{KM}$ & $\begin{array}{l}\text { Ground } \\
\text { LOC }\end{array}$ & $\begin{array}{l}\text { Future Truck } \\
\text { System }\end{array}$ & 5 hours \\
\hline $\begin{array}{l}\text { Sustainment } \\
\text { Force }\end{array}$ & $\begin{array}{l}\text { Support } \\
\text { Zone }\end{array}$ & MSS & $300 \mathrm{KM}$ & Air LOC & $\begin{array}{l}\text { Aerial } \\
\text { Vehicle }\end{array}$ & 1 hour \\
\hline $\begin{array}{l}\text { Sustainment } \\
\text { Force }\end{array}$ & $\begin{array}{l}\text { Support } \\
\text { Zone }\end{array}$ & MSS & $400 \mathrm{KM}$ & $\begin{array}{l}\text { Ground } \\
\text { LOC }\end{array}$ & $\begin{array}{l}\text { Future Truck } \\
\text { System }\end{array}$ & 8 hours \\
\hline
\end{tabular}

Table 1 Time and Distance Factors ${ }^{114}$

The support force will accomplish the SRS mission in seven hours and the MSS mission in fourteen hours using aerial vehicles. Both missions would take sixteen hours and twenty-eight hours respectively, using a future truck system. ${ }^{115}$ Given the time-distance factors and the operational scenario, support force commanders will have to determine an appropriate transportation mode to provide sustainment. Traditional factors such as mission, enemy situation, troops, terrain, and time available as well as civil considerations (METT-TC) will influence these decisions. However, a reduced CS/CSS footprint in the battle space will have greater importance because it is the overarching concept that makes achieving Objective Force design characteristics possible.

\footnotetext{
114 Travel times were estimated using straight-line distance for air and road distance for ground vehicles. These factors do not take into account potential delays caused by the environment or enemy actions.

115 The times were computed by adding the travel time to and from the sites with the time it took to complete the sustainment operations:

SRS by air $=0.5$ hours +6 hours +0.5 hours $=7$ hours .

MSS by air $=1.0$ hours +12 hours +1.0 hours $=14$ hours.

SRS by ground $=5$ hours +6 hours +5 hours $=16$ hours.

MSS by ground $=8$ hours +12 hours +8 hours $=28$ hours.
} 


\section{Criteria Review}

The design characteristics that will drive development of the Objective Force are the evaluation criteria for this monograph. For review, they are as follows:

Responsiveness: The ability to employ the right sustainment force that can provide the right support in the right place at the right time.

Deployability: The ability to prepare and move a force and its sustainment equipment and supplies to the area of operations.

Agility: The ability of friendly forces to rapidly adapt sustainment structures and procedures to changing mission requirements and to act faster than the enemy.

Versatility: The ability to rapidly and effectively shift focus from one operation to the other to support Objective Force mission transitions.

Lethality: The ability to generate and sustain combat power.

Survivability: The ability to protect support functions from destruction or degradation.

Sustainability: The ability to provide minimum essential sustainment to begin operations while providing continuous support throughout operations.

Based on research, the operational environment and the scenario, the following characteristics will be evaluated together: responsiveness with sustainability and versatility with agility. These characteristics are closely related and provide better clarity when examined together. Lethality was omitted because it did not provide a clear advantage based on transportation mode.

\section{Responsiveness and Sustainability}

"Responsiveness has the quality of time, distance, and sustained momentum." 116 It is similar to the CSS characteristic of responsiveness, but also includes aspects of focused logistics.

Sustainers must foresee operational requirements and provide the minimum capabilities to meet support requirements. ${ }^{117}$ Doing so requires task organizing the support force to quickly maximize

\footnotetext{
${ }^{116}$ United States Army Training and Doctrine Command. TRADOC Pamphlet 525-4-0, The United States Army Objective Force Maneuver Sustainment Operational and Organizational (O\&O) Concept (Draft 11 Feb 2002). By CASCOM CSS Battle Lab. Fort Monroe, 2002, 8.

${ }^{117}$ Department of the Army. Field Manual 3-0 Operations. Washington, DC, 2001, 12-3.
} 
its effectiveness and continuously sustaining operations over time. This relates to the characteristic of sustainability.

The support scenario above is an example of how supplies will traverse greater physical distances in the Objective Force era. Tactical logistics will occur from operational support distances because combat operations will commence without establishing in-theater sustainment bases. ${ }^{118}$ Most supplies will come directly from the continental United States (CONUS), another theater, a prepositioned location, or an intermediate staging base (ISB) This environment will demand that the sustainment and distribution system have three critical capabilities related to sustainability:

- Sufficient reach to connect the logistic pipeline to the supported force

- Sufficient capacity to continuously sustain the force

- The ability to provide time definite delivery

Sufficient reach is the ability to physically connect the sustainment base to the supported force. The system must be resilient enough to overcome terrain and enemy opposition. Capacity relates to the system's ability to provide sufficient sustainment to support an operation. The system must sustain maneuver organizations over time to prevent culmination. Time definite delivery is "the delivery of requested logistics support at a time and destination specified by the receiving activity." ${ }^{119}$ This relates to the requirement to provide focused logistics at operational distances without relying on multiple echelons of sustainment stocks. ${ }^{120}$

\footnotetext{
${ }^{118}$ Department of the Army. White Paper: Concepts for the Objective Force. Washington, DC, 2001. 12 Nov. 2001 <http://www.army.mil/features/WhitePaper/ObjectiveForceWhitePaper.pdf>, 1. The Objective Force will conduct operational maneuver from strategic distances and arrive ready to fight. Since operations must begin without building sustainment bases, sustaining tactical maneuver will occur from wherever the theater sustainment base is to the actual operation. These distances will be what are normally considered operational support distances.

${ }^{119}$ Department of Defense. Joint Publication 1-02, Department of Defense Dictionary of Military and Associated Terms. By Chairman of the Joint Chiefs of Staff. Washington, D.C.: US Government Printing Office, 2001, 441.

${ }^{120}$ Department of Defense. Joint Vision 2020. By Chairman of the Joint Chiefs of Staff. Washington, D.C.: US Government Printing Office, 2000, 24. Focused logistics is a JV 2020 concept.
} 
The physical reach of CSS systems will have the greatest impact on responsiveness in a theater of operations. During Operation Desert Storm, logistic planners used 90 miles (145 KM) as the distance to place subsequent logistic bases to sustain operations. This represented the distance that a soldier could drive in one day. ${ }^{121}$ Although the Army could expect a soldier's daily driving distance to increase in the upcoming decades, it may not increase dramatically. In the fictional scenario described earlier in this chapter, supporting the MSS operation required a twenty-eight hour ground sustainment operation, of which sixteen hours were spent driving. During vertical envelopment operations, times and distances could increase dramatically.

Objective Force operations may not require multiple logistic bases in the battle space, but if the distance were long enough, the presence of ground convoys over a period of days could create the same effect. Surface based sustainment may only be practicable within a limited area because of the reach of available transportation assets. The reach of an aerial based system would be significantly greater because the operator of an aerial vehicle could traverse hundreds of miles in hours. In the example above, the support force accomplished both the SRS and MSS operations within a reasonable duty day. An aerial based system would more likely to be able to reach Objective Force units throughout the battle space.

Another aspect of responsiveness is the ability to provide the right sustainment to the right place at the right time. This becomes increasingly difficult as the distance between the support and supported force increases. Longer distances equate to greater travel times and increased opportunity for en route changes. A sustainment system based on aerial vehicles would provide a higher velocity distribution pipeline whose momentum would not diminish throughout the battle space. Sustaining by air clearly provides better responsiveness and sustainability.

\footnotetext{
${ }^{121}$ LTG William G. Pagonis, and Harold E. Raugh. "Good Logistics is Combat Power." Military Review Sept. 1991: 37.
} 


\section{Deployability}

The Army's deployability goal is to put an Objective Force brigade anywhere in the world in 96 hours from first wheels up, a division in 120 hours and five divisions in 30 days. Deployability has strategic implications. It requires the Air Force and Navy to increase the velocity and capacity of their strategic lift assets, while the Army reduces its size and consumption of logistics. The Army's size and weight have the greatest impact on deployability.

Deployability involves Objective Force combat units, supplies and sustainment units. Combat units will be lighter, able to fit into smaller lift assets, require less sustainment, and will be more effective than current forces. As a result, fewer forces will have to deploy and this will ease some of the Army's strategic mobility challenges. Since the Objective Force will also consume less logistics, the Army will deploy reduced initial sustainment packages to commence combat operations.

The primary difference between a surface and aerial based sustainment and distribution system will be in how it deploys. An aerial based system will have a self-deployment capability. ${ }^{122}$ This will compress the Objective Force deployment sequence by freeing up limited strategic lift assets and allowing the Army to begin movement on its own terms. Accordingly, the Army's external strategic and operational lift requirements will decrease. Conversely, a surface based system will compete for the same lift assets as combat forces. Surface vehicles also require additional assets in preparation for deployment such as blocking and bracing. This will result in a relative increase in the lift requirements.

Aerial sustainment platforms provide additional benefits related to the ability to fly. They have greater operational CSS reach and will give the Army strategic mobility. This is an obvious advantage over a ground based sustainment system with limited reach and dependence on

\footnotetext{
${ }^{122}$ An aerial based sustainment system will not be based on current military aircraft such as Army helicopters and Air Force cargo airplanes. New aerial platforms will be significantly more capable than current systems. They will be able to operate in austere environments without fixed facilities such as airfields. Appendix 3 lists some of the proposed designs.
} 
external strategic lift. Once in theater, an aerial based sustainment system will give commanders the capability to reposition the support/security zone to better support ongoing operations.

\section{Versatility and Agility}

Versatility and agility are closely related from a logistic perspective. A versatile sustainment system will be able to rapidly support Objective Force transitions. Agile sustainment organizations will quickly task organize to meet mission requirements and act faster than the enemy. Accomplishing versatility and agility goals requires flexible sustainment leaders and adaptive organizations that can quickly adjust to the rapidly changing support requirements of Objective Force units.

In the Objective Force sustainment example earlier in this chapter, the Unit of Action conducted decisive operations, moved to a mission staging site, then transitioned to shaping operations. This required the support force to shift focus between sustaining the various types of operations. The obvious ability of being able to physically move between sites quicker gives an aerial based system an advantage. An extended drive to an SRS or MSS could give sustainers limited ability to shift focus based on changing mission requirements.

Agility is a combination of information and situational awareness with the speed and adaptability of sustainment organizations. Supporting the Unit of Action by ground required initiation of movement at least five hours prior to the SRS and eight hours prior to the MSS. Even given perfect information on the Unit of Action sustainment requirements, by the time the convoy arrived, the situation may have changed. The support force would have an extremely limited ability to do adjust to these changes. Sustaining by air would give the support force the ability to adjust the needed logistics during support operations.

Agility also has an aspect related to enemy forces where aerial platforms have advantages over ground vehicles. Objective Force units will see first, understand first, act first and finish decisively. Given an accurate ability to detect threats, Objective Force sustainment units should 
be able to avoid becoming decisively engaged by the enemy. An aerial line of communication provides commanders more flexibility to act faster than the enemy and maneuver out of contact.

Units of Action can select SRS or MSS sites that are favorable to ground or aerial sustainment, but the support force will have to use available routes to these sites. Ground lines of communication are more vulnerable to the enemy's use of natural and man made obstacles. Even if these obstacles are detected, the actions required to avoid or reduce them may significantly increase travel time and reduce the ground support force's agility.

\section{Survivability}

Survivability involves protection of support functions. Sustainment organizations must protect their information systems and physical distribution networks. At the operational level, the physical distribution network begins in the support/security zone and extends to link up sites with Units of Action such as SRS and MSS. The difference between aerial or ground based sustainment systems will be the ability to provide protection along lines of communication.

A surface based sustainment and distribution system will be threatened by ground attacks. These could be ambushes from small, guerrilla type forces or military forces. Ground systems are vulnerable to the effects of dense populations around urban areas. In some cases, terrain will dictate where surfaced based forces must go, and the enemy can exploit this predictability. Finally, a surface based system will be exposed to the enemy for relatively longer periods of time.

The primary threat to aerial vehicles will be from surface to air missiles because US forces will have air superiority in any area they operate in. Aerial vehicles will have embedded aircraft survivability systems and will benefit from the protection of US Air Force efforts to suppress enemy air defenses. Compared to ground vehicles, aerial platforms will be exposed to enemy systems for relatively shorter periods of time. This gives the aerial sustainment system greater survivability. 
An additional aspect of survivability is the capability to move the support/security zone to better support Units of Action or in response to anticipated enemy action. At D+4 in the Objective Force sustainment example, the Unit of Action would be over $600 \mathrm{KM}$ away from the support/security zone by ground line of communication. This would necessitate moving the support/security zone to reduce the line of communication to increase responsiveness and decrease exposure to the enemy while in transit inside the battle space. The ground based unit would have to conduct this move with intra-theater lift or by traveling through the battle space.

Sustainment units might have to move the support/security zone based on anticipated enemy action. These actions could include targeting by ballistic missiles or imminent attack. Assuming that all Objective Force sustainment organizations will be 100\% mobile, aerial based units will have an advantage when required to reposition. They will be able to move faster and relocate to another support/security zone without occupying an area within the battle space. Increased mobility and reduced exposure to the effects of enemy weapons systems gives the aerial based system significant advantages over a ground based system.

\section{Overall Assessment}

An aerial based sustainment system best supports the Objective Force in a high intensity environment that uses Army forces for rapid decisive operations. This same sustainment system would also be capable of supporting the Objective Force in a less demanding environment, but the advantages over ground vehicles would decrease. An aerial based system gains its advantages by its ability to rapidly traverse extended lines of communication, quickly adjust to changing support requirements and limit exposure to enemy weapons systems. 


\section{CHAPTER SIX}

The ultimate test of any military transformation is its relevance to the evolving challenges with which it is confronted.

$\underline{\text { TRADOC PAM 525-4-0, Objective Force Maneuver Sustainment }}$

\section{CONCLUSIONS AND RECOMMENDATIONS}

A logical solution to the challenges of Objective Force sustainment is to develop an aerialbased sustainment and distribution system. Sustaining from the air supports vertical envelopment and offers the ability to rapidly sustain Objective Force units as they maneuver across long distances. Such a system allows greater responsiveness, agility and survivability while increasing CSS reach. It will also increase logistic velocity, provide for execution of time definite deliveries and reduce the logistics footprint in the battlespace. Finally, given the proper aerial vehicles, an aerial-based sustainment system could reduce theater distribution infrastructure requirements while improving capacity and control. Given the expected operational environment, the Army cannot successfully execute its Objective Force transformation without an operational level aerial-based sustainment and distribution system.

Despite the apparent advantages to an aerial-based sustainment system, the challenges are daunting. Implementing such a system will require changes across Army the DTLOMS and throughout the joint community. Army logistic units have not had dedicated airlift, although joint and Army airlift assets have been temporarily tasked for Army sustainment. Creating this new distribution capability for the Army sustainment community is a tremendous challenge, but it is one that must be met. Virtually every document that describes sustaining the Objective Force identifies the need for aerial sustainment. The Objective Force Maneuver Sustainment 
Operational and Organizational Concept not only recognizes the need for dedicated aerial sustainment, but presupposes it will be embedded in future sustainment organizations. ${ }^{123}$

The consensus from experimentation is clear. The Army's Objective Force sustainment community needs a dedicated aerial sustainment capability. The elusive questions are what aerial platforms could meet the requirement, and will the Army or Defense Department invest in developing them? Even if a number of current Army or joint air platforms were dedicated strictly for Army sustainment operations, the systems could not support the Objective Force. Cargo helicopters do not have the range or lift capacity, and cargo airplanes require too much infrastructure. CSS Transformation must produce new aerial platforms that are capable of supporting the Objective Force.

Some of the systems under consideration are the Joint Transport Rotorcraft (JTR), Future Transport Rotorcraft (FTR), Advanced Tactical Transport (ATT), and lighter-than-air rigid and semi-rigid airships known as Ultra Large Airlifters (ULA). Additional systems remain to be developed such as the Light Aerial Multipurpose Vehicle (LAMV). ${ }^{124}$ All of these systems are considered Objective Force logistics enablers. However, as of November 2001, the Army's Deputy Chief of Staff, G4 reported that research for the LAMV and FTR was not funded. ${ }^{125}$ Considering that current aerial platforms will not meet Objective Force sustainment requirements, the Army should aggressively pursue development and acquisition of these logistics enablers.

Sustaining the Objective Force in a full spectrum environment will depend on continuous multi-modal sustainment with a greater dependence on the aerial component. The requirement for surface-based sustainment will not significantly diminish in the next decade because the Army will have to support Legacy, Interim and Objective Forces. However, the Army's sustainment

\footnotetext{
${ }^{123}$ United States Army Training and Doctrine Command. TRADOC Pamphlet 525-4-0, The United States Army Objective Force Maneuver Sustainment Operational and Organizational (O\&O) Concept (Draft 11 Feb 2002). By CASCOM CSS Battle Lab. Fort Monroe, 2002, 21, 33.

${ }^{124}$ See appendix 2
} 
community should begin a deliberate effort to transform its sustainment model from a primarily surface to aerial based model. Doing so will require changing the Army's sustainment culture, organizations, materiel and doctrine.

\section{Cultural Change}

There are two aspects to cultural change: the sustainment force and the maneuver force. The Army is well on its way to accomplishing its goal of transforming its sustainment community culture. The Army's Velocity Management initiatives began in the mid-1990s as a way of transforming the Army's logistics system from a mass to velocity based system. The smaller, power projection Army could no longer afford the system of forward deployed stockpiles created during the Cold War. Velocity Management achieves greater efficiencies and has also been more effective in supporting war-fighting commanders worldwide. ${ }^{126}$ These represent procedural and conceptual changes, but the Army needs further change to fully transform the Army sustainment culture.

\footnotetext{
${ }^{125}$ Charles S. Mahan, Lieutenant General. "Transforming to the Objective Force.” Objective Force Task Force Web Site. 8 Nov. 2001. PowerPoint Briefing. <http://www.objectiveforce.army.mil/oftf/Briefings/AUSA/LTG\%20Mahan.zip>

${ }^{126}$ Wang, Mark Y.D., and James A. Champy . "Chapter 2: Institutionalizing the Velocity Management Paradigm.” Accelerated Logistics: Streamlining the Army's Supply Chain. 2000. 2000. Rand. 5-8. 25 Mar. $2002<$ http://www.rand.org/publications/MR/MR1140/>, 5.
} 


\begin{tabular}{|c|c|c|}
\hline Characteristic & $\begin{array}{l}\text { Traditional Army } \\
\text { logistics concept }\end{array}$ & $\begin{array}{l}\text { New Army } \\
\text { logistics concept }\end{array}$ \\
\hline View of logistics & Piles of "things" & $\begin{array}{l}\text { Set of processes to meet customer } \\
\text { needs }\end{array}$ \\
\hline $\begin{array}{l}\text { View of the logistics } \\
\text { system }\end{array}$ & $\begin{array}{ll}\text { Function (provider) } \\
\text { - } \\
\text { - Ordnartermaster } \\
\text { - } \quad \text { Transportation } \\
\end{array}$ & $\begin{array}{l}\text { Process (customer) } \\
\text { - } \quad \text { Order and ship } \\
\text { - } \quad \text { Repair } \\
\text { - Stockage } \\
\end{array}$ \\
\hline Metrics & $\begin{array}{l}\text { Days of supply } \\
\text { Shop repair cycle time }\end{array}$ & $\begin{array}{l}\text { Time, quality, cost } \\
\text { Total repair cycle time }\end{array}$ \\
\hline Reporting & Average performance & Median performance, variance \\
\hline $\begin{array}{l}\text { Orientation of } \\
\text { managers }\end{array}$ & $\begin{array}{l}\text { Compliance oriented } \\
\text { Dedicated resources } \\
\text { Free issue } \\
\text { Inspection/review/control } \\
\text { Incremental improvement }\end{array}$ & $\begin{array}{l}\text { Mission oriented } \\
\text { Flexible resources } \\
\text { Pricing incentives } \\
\text { Visibility/system understanding } \\
\text { Continuous improvement }\end{array}$ \\
\hline
\end{tabular}

Sustaining the Objective Force will require an operational level sustainment and distribution system with far greater reach than the current system. Changes in the battlefield framework will cause sustainers to maneuver along unsecured lines of communications without the benefit of protection from operating in rear areas. Protecting the distribution system will require combat power that may have to be organic to the sustainment organization. Leaders will have to integrate maneuver, fires and intelligence into logistics missions that will have an offensive spirit. The result must be a sustainment warrior culture capable of rapid and assured sustainment to the maneuver force in any environment.

The second aspect of required cultural change involves the maneuver force and the confidence in the sustainment system. Maneuver commanders understand the constraints and limitations that the logistics force imposes on maneuver. However, they also recognize the requirement for logistics mass to support heavy forces. A long-standing industrial age sustainment challenge has been how to enable a maneuver force to conduct operations without the constraints imposed by the logistics system?

\footnotetext{
127 Source: Wang, Mark Y.D., and James A. Champy . "Chapter 2: Institutionalizing the Velocity Management Paradigm.” Accelerated Logistics: Streamlining the Army’s Supply Chain. 2000. 2000. Rand. 5-8. 25 Mar. $2002<$ http://www.rand.org/publications/MR/MR1140/>, 7.
} 
The current logistics system is constrained and limited by its reliance on ports of debarkation and ground lines of communication to provide the mass quantities of sustainment to current forces. In the Objective Force era, some of these challenges will be solved with force design improvements that reduce the requirement for logistics support. ${ }^{128}$ Other challenges will be solved by improvements in the sustainment and distribution system. However, regardless of the improvements, the Objective Force, like every other Army force in history, will have to contend with a logistics tail.

War fighting commanders throughout time have sought the panacea of prosecuting battles without the constraint of logistics. This state will never be achieved. At no point in the future will any combat system be completely free from a logistics tail. A logistics tail consists of a war fighting organization's sustainment base(s) and distribution networks within its area of operation. This includes the associated sustainment organizations and materiel stocks. ${ }^{129}$ Technological advances, doctrinal and procedural changes may shift the location of the logistics tail, but it will never be eliminated.

Weapons systems will always be manufactured, transported, integrated into a theater of operations and operate for a finite time before failure. At some point, that system will need to be externally maintained, resupplied or replaced. This applies to units, men, machines and animals alike. At its most fundamental level, sustainment is about providing the inevitable resupply of all systems on the battlefield. Therefore, since every war fighting organization will always require resupply and maintenance, it will likewise always have sustainment bases and distribution networks. War fighting commanders must decide where to put them, how to protect them, and how best to employ logistics to sustain the fight.

\footnotetext{
${ }^{128}$ Department of the Army. White Paper: Concepts for the Objective Force. Washington, DC, 2001. 12 Nov. 2001 <http://www.army.mil/features/WhitePaper/ObjectiveForceWhitePaper.pdf>, 9.

129 "Logistics Tail" is not an official Department of the Army or Department of Defense Term, although it is commonly used. The description in the text includes the elements most commonly referred to when the term is used.
} 
The Objective Force sustainment concept seeks to reduce the logistics footprint in theater, but does not eliminate it. Achieving the reduced footprint goal will not be realized until there are drastic reductions in demand, and this is not a logistics function. It is a characteristic of the weapons system. Systems like the FCS will bring this reduced demand to the Objective Force and this will change the sustainment paradigm. Units will not receive daily resupply and higher echelon logistics units and sustainment stocks will be further away. Maneuver commanders must contend with the implications of this system.

There are three aspects of the logistics system that have historically given a maneuver commander assurance: mass, close proximity and control over the sustainers. Organizationally and culturally, maneuver commanders have been trained to ensure there is sufficient mass in their logistics tail. At the brigade level, the logistics tail is a Brigade Support Area (BSA), Forward Support Battalion (FSB) and Main Supply Routes (MSR). It could even include corps level convoys that throughput supplies to the brigade. At the operational level, the logistics tail includes sustainment bases, logistics organizations and lines of communication from ports of debarkation to the battle areas. ${ }^{130}$ At every level, maneuver commanders have made decisions to ensure they have sufficient logistics to conduct operations.

Desert Storm provides insight on how building logistics mass affected a theater commander's organization for combat. General Norman Schwarzkopf determined 60 days of supply in theater as the point at which his forces could begin combat operations. ${ }^{131} \mathrm{He}$ was concerned about the effect a potential disruption of the logistics pipeline might have on operations. The build up took almost six months and involved large logistics bases connected primarily by surface modes. Once the build up was complete, General Schwarzkopf's confidence increased because he had control of the required logistics.

\footnotetext{
${ }^{130}$ See appendix 4

131 GEN Norman Schwarzkopf as quoted in_Peter C. Langenus, "Moving an Army: Movement Control for Desert Storm.” Military Review Sept. 1991: 40-51. 8 Jan. 2002
} 
Maneuver commanders' assurance in the Army's Cold War logistics system resulted from logistics mass created by sustainment bases and linked by reliable transportation. These perceptions must change in order to successfully execute Army Transformation. These will only change when the Army sustainment community consistently demonstrates a reliable distribution based sustainment system, and this will take time. Key to this success is having the proper enabling technologies. The Army is making progress, but has not been fully successful.

In 1999 the Army conducted a logistics oriented rotation at the National Training Center as part of its ongoing CSS redesign efforts. Some of the rotation's goals were to exercise limited CSS enabling systems and a distribution-based system. ${ }^{132}$ The main participant was the 1 st Brigade Combat Team, 4th Infantry Division that was also one of the Army's first digital brigades. After the rotation, the 1st BCT commander, COL Rick Lynch, was cautious in his assessment of the benefits of CSS redesign. ${ }^{133}$ Logistics permitted successful operations at the NTC even though all of the digital enablers were not present.

However, COL Lynch perceived that success was the result of the mass of logistics provided by the corps support group and division sustainment cell. The attempt at distribution-based sustainment was not credited with the success. ${ }^{134}$ COL Lynch's experience at the NTC is not an indictment of ongoing CSS Transformation efforts. CSS redesign efforts advanced as a result of the rotation. Rather it illustrates the importance of holistic transformation efforts not only across DTLOMS, but Army culture as well.

Confidence in the sustainment system is a result of proven success in the operational environment. This will come with better operational integration, improved situational understanding and the physical ability to deliver required support using a distribution-based

<https://calldbpub.leavenworth.army.mil/eng_mr/text/Vol71/00000009/art041_8.pdf\#xml=https://calldbpu b.leavenworth.army.mil/temp_dir/hltd414F2737.pdf>, 1 .

${ }^{132}$ Eric E Smith,. "A Logistics-Focused NTC Rotation.” Army Logistician Sept. 1999. 1 Apr. 2002 <http://www.almc.army.mil/ALOG/issues/SepOct99/MS473.htm>

${ }^{133}$ Lynch, Rick. Personal Interview. Summer 1999.

${ }^{134}$ Ibid. 
system. The Cold War logistician assured maneuver commanders through the proven technique of building mass and reliable surface transportation modes. The Objective Force maneuver sustainer will have to build confidence through a proven and reliable distribution based sustainment system that is capable of extended CSS reach. Such a system will have to rely on aerial distribution modes.

Once such a system is in place, maneuver commanders will have more agility in the combat zone, but they will have different sustainment challenges. Potential adversaries will know how Army forces sustain and will seek to interdict the distribution networks and lines of communication. The Air Force is responsible for maintaining air lines of communication in a theater, but the Army may have to reduce threats such as man portable air defense systems (MANPADS). Also, Army forces may have to maneuver to sustainment and replenishment sites instead of having the sustainment simply follow the force. Objective Force operations will create a new paradigm for how forces operate and are sustained.

The challenges described above will require changing the most important element of combat power, soldiers. Maneuver commanders will have to think differently about sustainment and how it is integrated into operations. They will have to avoid a tendency to stockpile in the combat zone, "just-in-case" and sustainers will have to continuously provide rapid and assured sustainment worldwide and in any environment. Sustainment must be viewed less as an administrative task and more like an integrated tactical or operational mission. This fusion of logistics and operations will call for organizations with new competencies.

\section{Organizational Change}

The aerial sustainment mission will require these organizations to operate over distances far greater than today's logistics forces. Currently most Army sustainment missions are conducted on the ground where distances and capabilities are measured in terms of local haul (20 miles) and line haul (90 miles). At the operational level, Objective Force sustainment organizations will 
continue to use surface modes, but will also have an organic aerial sustainment capability that extends over hundreds of miles. Increased command and control as well as interoperability at the joint level will be necessary.

The Army's current logistics organizations at the theater, corps and division level manage materiel, control movements and perform mode operations. The Army Service Component Command (ASCC) is responsible for surface modes and the Air Force Service Component Command (AFCC) is responsible for air modes. Since the Army's organic CH-47 helicopters limit operational airlift support, it must coordinate with the Air Force for intra-theater airlift normally accomplished by $\mathrm{C}-130$ aircraft. This requires coordination through movement control centers, G4, G3 and Air Force liaison channels. ${ }^{135}$ Objective Force Army sustainment organizations may have platforms similar to the $\mathrm{C}-130$ and should be able to plan and execute aerial sustainment missions accordingly.

Army sustainment staffs are oriented toward operating on the ground because aerial sustainment is conducted by exception. Weather, enemy and terrain are interpreted through the prism of effects on surface operations. Sustainment staffs will have to incorporate aerial considerations and develop plans that maximize the flexibility of the Army's multimodal capability. Staffs will need to know the status of air lines of communication and enemy air defense capabilities. Army sustainment organizations will have to have air traffic services, even though the Air Force will still have responsibility for air lines of communication. True situational understanding for the Objective Force sustainer will involve having real-time visibility of all elements of the distribution pipeline as well as anything that could potentially interrupt it.

Making aerial sustainment a core competency for the Army will require knowledge based organizations centered on sustainment warriors. This will be enabled by communications and information management improvements, but will not be completely realized until the Army has significant advances in the physical distribution network. Aerial sustainment should be embedded 
in the Army sustainment community's culture without losing focus on its primary mission of supporting the war fighter. Maneuver sustainment should not become the air mobility component of the Army, but should continue to serve as a component of the combined arms team. ${ }^{136}$

\section{Materiel Change}

Transforming the Army's culture and organizations will require evolutionary changes over time. The most revolutionary changes required to transform the Army's sustainment community will be materiel changes because of how it impacts the Army aviation branch and the Air Force. The Army needs a capability that neither the Air Force or Army aviation has in development nor can currently provide. Solving these issues will require a significant review of roles and missions, but this is beyond the scope of this monograph. It is important to recognize however, that Objective Force operational requirements are leading toward a materiel solution of dedicated airlift assets supporting an aerial based sustainment and distribution system.

Army forces and operations are becoming increasingly expeditionary. ${ }^{137}$ Objective Force operations will be even more so. Achieving the rapid deployment goals of the Objective Force will require prepositioned stocks and fast sealift, but it almost necessitates a greater reliance on a robust strategic air mobility capability. Objective Force units will conduct operational maneuver from strategic distances to build and sustain overwhelming combat power anywhere in the world. The mobility of the sustainment force will greatly impact the maneuver force's ability to conduct its mission.

Maneuver sustainment mobility must increase for three reasons. First, the Objective Force demand will be drastically reduced. Second, the CSS footprint in the combat zone will be reduced. Third, lines of communication in the Objective Force era will be extended. The addition of a new aerial sustainment capability best supports this force for reasons previously mentioned

${ }^{135}$ Department of the Army. Field Manual 55-1 Transportation Operations. Washington, DC, 1995, 5-16.

${ }^{136}$ Department of the Army. Field Manual 1-100 Army Aviation Operations. Washington, DC, 1997, 1-3. This is similar to the principle that recognizes that Army Aviation operates in the ground regime.

${ }^{137}$ Department of the Army. Field Manual 100-10-1 Theater Distribution. Washington, DC, 1999, 1-1. 
and that the sustainment force will gain the ability to self deploy. Maneuver sustainment organizations will support Objective Force deployability goals by occupying less space on Air Force strategic airlift and by deploying a portion of itself.

The Air Force relies on prepositioned stocks and sealift, but applies the model of selfdeploying a portion of its sustainment force. A 2001 air mobility study from the Air Power Research provided two relevant conclusions: "expeditionary Air Force operations require a dedicated airlift fleet" and operating in "austere Third World countries requires a self-sustaining airlift forces." ${ }^{\prime 138}$ The author examined Air Force operations in the Congo from 1960 - 1978. Although the Army operates differently than the Air Force, the Objective Force could face many of the challenges described in the study. Undoubtedly, Objective Force operations could be greatly enhanced by an aerial-based sustainment and distribution system. Lacking such a system will almost certainly constrain Objective Force operations.

\section{Current System Constraints}

Aircraft available to meet Army operational level airlift requirements are its fleet of CH-47D helicopters and the Air Force fleet of C-130 aircraft. The CH-47D is being upgraded to the $\mathrm{CH}-$ 47F that will improve its engines and situational awareness capabilities. Even with the upgrades, the helicopter's range will limit its usefulness in operating with Objective Force units. It will not be able to lift the FCS and will require too much infrastructure in the combat zone.

The C-130 is a more capable aircraft in supporting the Objective Force. The FCS is being designed to fit inside a C-130 although that may not mean that the $\mathrm{C}-130$ is the ideal transport aircraft. The C-130 will be capable of transporting the FCS, but as figure 3 below shows, greater weights significantly reduce the operating range. The ranges reflected below assume a 5,000 foot improved runway with fuel available. These infrastructure requirements also limit the usefulness of the C-130 in supporting the Objective Force. 


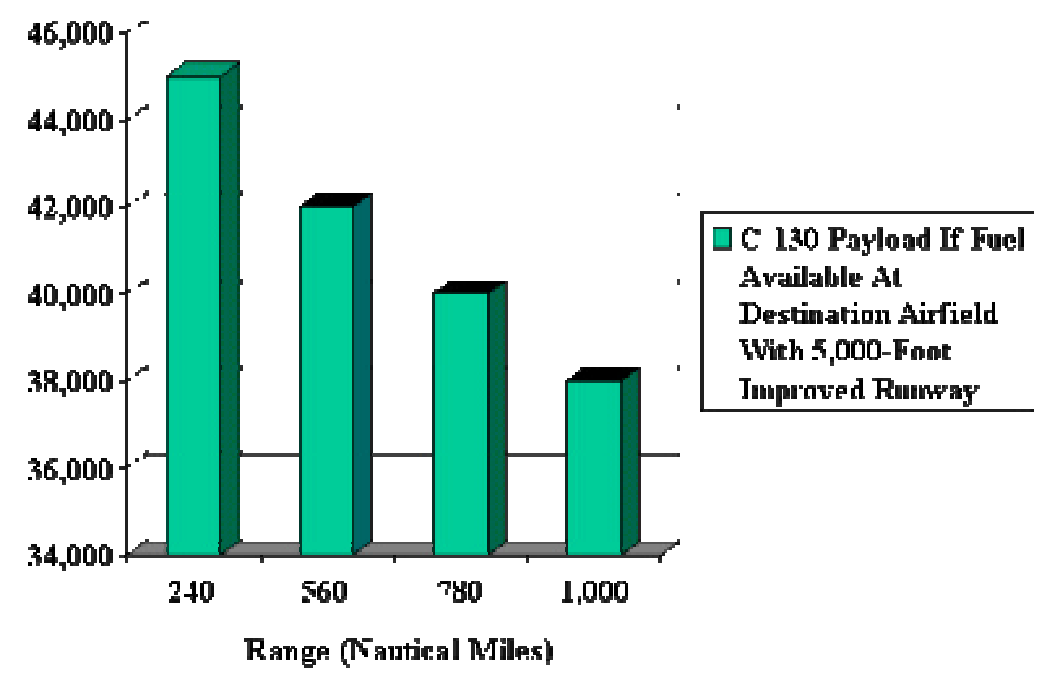

Figure 5 C-130 Payload and Range ${ }^{139}$

There have been detailed studies of both the $\mathrm{CH}-47$ and $\mathrm{C}-130$ operating in a variety of environments with different payloads. Both aircraft can be modified to provide users different mobility options based on configuration. However, neither aircraft has the range and capacity coupled with vertical takeoff and landing (VTOL) or super short takeoff and landing capability (SSTOL) that would give the Objective Force required mobility. TRADOC PAM 525-66, Future Operating Capability, defines SSTOL as follows:

Capability to employ an unimproved runway. Must meet Transportation Corps Strategic Vision of delivering a minimum of 30 tons on a runway of 750 feet or shorter. Will provide short landing strip cargo delivering capability through improved containers and delivery systems. ${ }^{140}$

Aerial platforms that support the Objective Force will have SSTOL and VTOL capabilities. There are conceptual designs, but none have been delivered. The Army does not have a cargo aircraft programmed to replace the $\mathrm{CH}-47$ and the Air Force has not yet designated a C-130

\footnotetext{
${ }^{138}$ Gilles K. Van Nederveen, "USAF Airlift into the Heart of Darkness, the Congo 1960-1978: Implications for Modern Air Mobility Planners.” Airpower Research Institute. 25 Mar. 2002 <http://research.au.af.mil/papers/special_collection/arr/2001-04.pdf〉, 57.

${ }^{139}$ Source: C-130 paper Cassidy, Joseph F. C-130 Transportability of Army Vehicles. N.p.: Military Traffic Management Command Transportation Engineering Agency, 2001.

${ }^{140}$ United States Army Training and Doctrine Command. TRADOC Pamphlet 525-66, Future Operational Capability. Fort Monroe, 1997, 144.
} 
replacement. As the Objective Force concept matures, the Army should pursue a strategy to replace the $\mathrm{CH}-47$ with an aircraft or series of aircraft that give it the required capabilities.

\section{Centerpiece Enabler}

The FCS is the centerpiece materiel enabler for Army Transformation. The sustainment community should place similar emphasis on a sustainment materiel enabler such as an aerial sustainment vehicle. This aerial vehicle or series of vehicles will serve to bridge the gap between the information network and the physical distribution network in the Objective Force era. Given the growth of computer technologies, the Army is likely to achieve its information and asset visibility goals. However, unless the Army aggressively adopts a strategy to develop additional aerial sustainment capabilities, it may not achieve its sustainment and distribution goals.

\section{Aerial Vehicles}

There are three categories of aerial vehicles the Army should consider: light, medium and heavy. A light aerial vehicle will be capable of moving personnel and small amounts of equipment up to one and a half tons. A medium aerial vehicle should be capable of carrying one FCS. Heavy aerial vehicles should be capable of carrying multiple FCS. Light and medium could be used at the operational or tactical level and heavy aerial vehicles could be used at the strategic or operational level. All aerial vehicles should also have additional capabilities that are different than current aircraft.

Advances in avionics and navigation may allow aerial vehicles to require operators and not pilots. A pilot requires advanced flight training to fly an aircraft. An operator would require minimal training to operate an aerial vehicle because internal computers would do most of the work. Some vehicles may one day not require a pilot at all, but this will require further study of the implications. Reducing the training requirements will be key to integrating aerial vehicles into the sustainment system. This will probably be more difficult with heavier aerial vehicles. 
The Light Aerial Multipurpose Vehicle (LAMV) concept is based on the Moller Sky Car. This will be a VTOL aerial vehicle capable of speeds up to $350 \mathrm{MPH} .^{141}$ Design constraints will limit its cargo capacity to around one and a half tons, but it does show promise. Another concept that could potentially fill the light aerial vehicle requirement is the gyroplane. CarterCopters has a flying version of its prop gyroplane with plans for a jet version. ${ }^{142}$

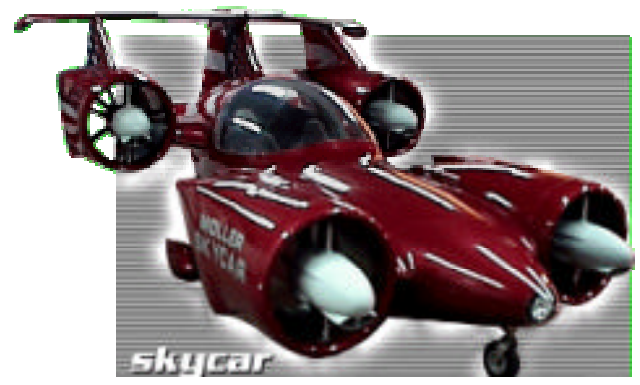

Figure 6 - Moller Sky Car Concept (LAMV)

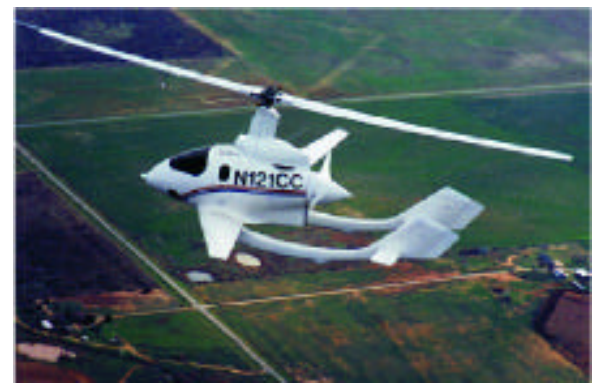

Figure 7 CarterCopter Prop Gyroplane (LAMV)

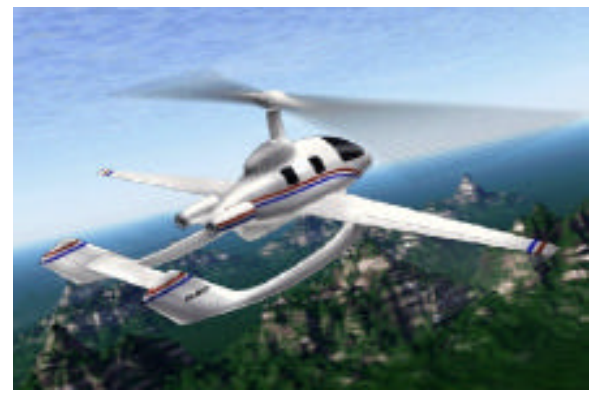

Figure 8 CarterCopter Jet Gyroplane Concept (LAMV)

Light aerial vehicles could perform tasks such as personnel distribution, movement control and reconnaissance. The Objective Force's reduced demand for logistics could also make these

${ }^{141}$ Moller International. 2 Jan. $2002<$ http://www.moller.com/>

142 CarterCopters. 3 Jan. $2002<$ http://www.cartercopters.com/> 
viable resupply vehicles for other than fuel, ammunition or major end item resupply. Perhaps the most critical logistics task performed by light aerial vehicles could be aeromedical evacuation because Objective Force operations may occur beyond the range of aeromedical evacuation helicopters. The Army should definitely develop a light aerial vehicle capability and consider developing a medium aerial vehicle capability.

Medium aerial vehicles will give the Army the capability to execute vertical maneuver by their capability to lift an FCS. This capability will also result in the ability to provide fuel, ammunition and major end item resupply to the Objective Force. Current concepts include the FTR, JTR and ATT. One of the most promising technologies is the heliplane being developed by CarterCopters.
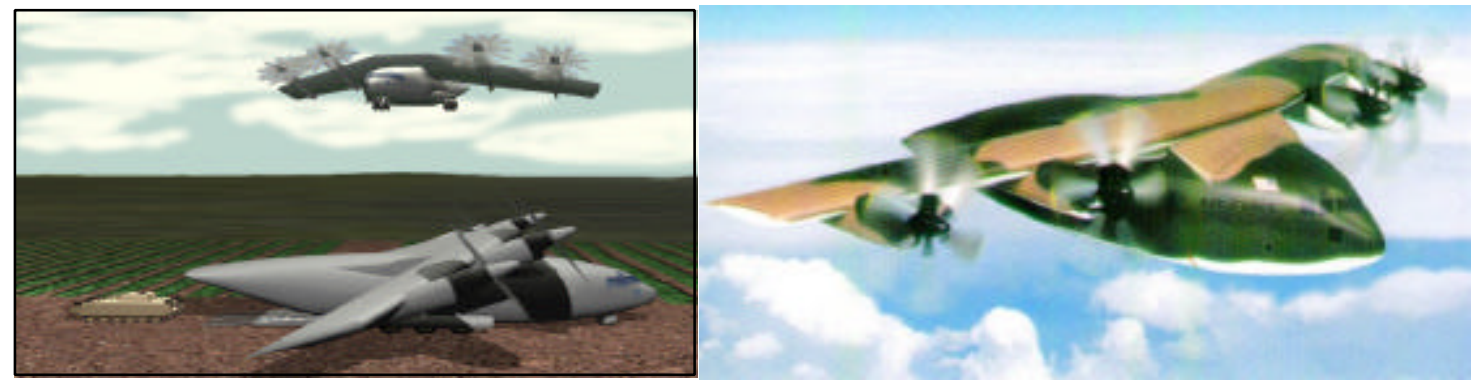

Figure 9 FTR, JTR, ATT Concept Designs

The heliplane is based on gyroplane design and looks like a cross between a helicopter and a C-130. It will have VTOL and SSTOL capability and should be able to carry an FCS internally or externally. It should have a range of 800 miles with a 45,000-pound load in a VTOL profile. Range and payload will increase in an SSTOL profile. ${ }^{143}$ This concept is simply in the design phase, but should be seriously considered for Army air mobility.

\footnotetext{
${ }^{143}$ Appendix 2 lists these characteristics
} 

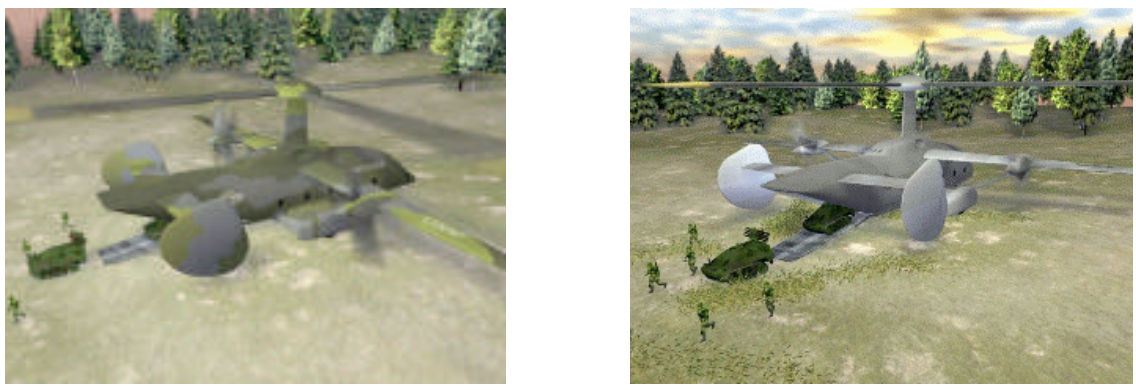

\section{Figure 10 CarterCopter Heliplane Concept}

The Ultra Large Aircraft (ULA) designs are based on rigid and semi-rigid airships. The Air

Force should develop these aircraft to supplement other modes of strategic airlift. ULA could also be used for intra-theater airlift based on terrain and threat environment.
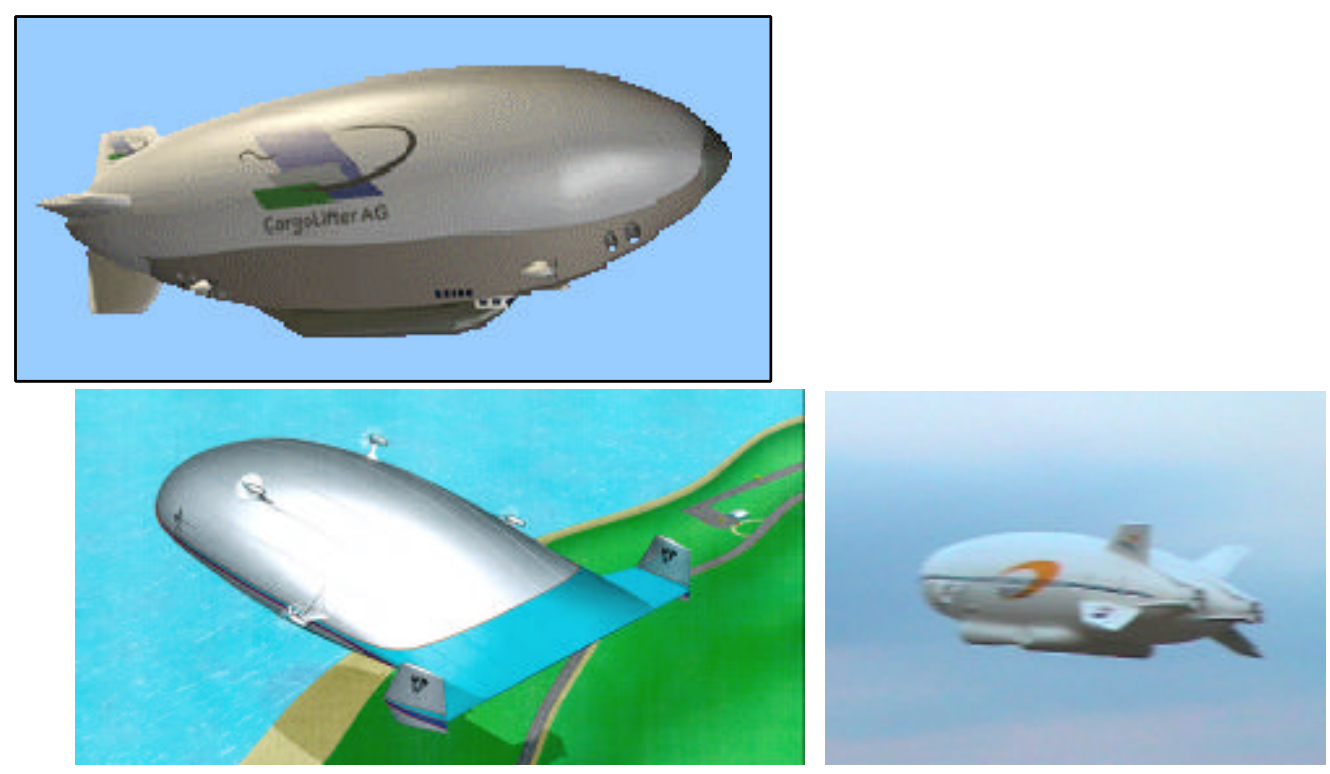

Figure 11 Various ULA Airship Concepts

Making aerial sustainment a core competency will give the Army the ability to perform its mandated mission of providing logistics support to its force. Much of the previous work already done on this subject suggests a heavy reliance on aerial sustainment for the Objective Force. Implementing such a system is a significant fiscal investment that will require reviewing roles and missions.

The Army should 
- Transform its sustainment culture. Rapid and assured sustainment will build confidence, not close proximity of a logistics mass.

- Transform its sustainment organizations to execute operational level multimodal sustainment operations in any environment.

- Make a medium-weight aerial transport vehicle the centerpiece materiel enabler of CSS Transformation. Develop in parallel with the FCS.

- Take the initiative in reviewing roles and missions to ensure it retains critical capabilities.

Transforming the Army's sustainment community will require change across DLTOMS. The Army will continue to sustain its forces using surface modes especially to provide support to other services and allies. However, sustaining the Objective Force will require an organic aerial sustainment capability. 


\section{APPENDIX 1 - Transportation Mode Capabilities and Limitations}

\begin{tabular}{|c|c|c|c|}
\hline $\begin{array}{l}\text { ORDER OF } \\
\text { ECONOMY }\end{array}$ & $\begin{array}{l}\text { MOST EFFECTIVE } \\
\text { USE }\end{array}$ & CAPABILITIES & LIMITATIONS \\
\hline Pipeline & $\begin{array}{l}\text { Primary mode for } \\
\text { bulk liquids and solids } \\
\text { suspended in liquid. }\end{array}$ & $\begin{array}{l}\text { All weather } \\
\text { conditions, few terrain } \\
\text { restrictions, most } \\
\text { economical and } \\
\text { reliable mode for bulk } \\
\text { liquids, relatively few } \\
\text { personnel required for } \\
\text { operation and } \\
\text { maintenance. }\end{array}$ & $\begin{array}{l}\text { Flexibility limited by } \\
\text { immobile facilities, } \\
\text { vulnerable to sabotage } \\
\text { and enemy action, } \\
\text { large construction } \\
\text { tonnages required. }\end{array}$ \\
\hline Sea & $\begin{array}{l}\text { Primary over-ocean } \\
\text { mode. Inland surface } \\
\text { mode for moving } \\
\text { large quantities of } \\
\text { cargo. }\end{array}$ & $\begin{array}{l}\text { All weather } \\
\text { conditions, any } \\
\text { commodity, most } \\
\text { economical overall } \\
\text { long-distance carrier, } \\
\text { particularly useful for } \\
\text { relieving other modes } \\
\text { to more suitable } \\
\text { employment. }\end{array}$ & $\begin{array}{l}\text { Relatively slow, } \\
\text { flexibility limited by } \\
\text { adequacy of } \\
\text { waterways, facilities, } \\
\text { and channels, } \\
\text { vulnerable to enemy } \\
\text { action and difficult to } \\
\text { restore. Also, inland } \\
\text { waterways subject to } \\
\text { flooding and freezing. }\end{array}$ \\
\hline Rail & $\begin{array}{l}\text { Primary inland mode } \\
\text { for sustained flow of } \\
\text { large quantities of } \\
\text { traffic over long } \\
\text { distances. }\end{array}$ & $\begin{array}{l}\text { All weather } \\
\text { conditions, any } \\
\text { commodity, most } \\
\text { economical } \\
\text { continuous line-haul } \\
\text { operations, greatest } \\
\text { sustained ton-mile } \\
\text { capability, variety of } \\
\text { specialized equipment } \\
\text { and services. } \\
\end{array}$ & $\begin{array}{l}\text { Flexibility limited by } \\
\text { fixed routes, rail-line } \\
\text { clearances restrict } \\
\text { outsize movements, } \\
\text { capability limited by } \\
\text { availability of tractive } \\
\text { power, rail-line highly } \\
\text { vulnerable to enemy } \\
\text { action. }\end{array}$ \\
\hline Highway & $\begin{array}{l}\text { Supplementary mode } \\
\text { for making possible } \\
\text { an integrated } \\
\text { transportation system. } \\
\text { Effective in scheduled } \\
\text { line-haul operations } \\
\text { by the trailer relay } \\
\text { system, primary mode } \\
\text { for distribution } \\
\text { operations and } \\
\text { logistical support } \\
\text { operations in combat } \\
\text { zone. }\end{array}$ & $\begin{array}{l}\text { Most flexible mode } \\
\text { over trafficable } \\
\text { terrain, practically all } \\
\text { weather conditions } \\
\text { (terrain factor } \\
\text { important), increased } \\
\text { flexibility of other } \\
\text { modes, can transport } \\
\text { nearly any commodity } \\
\text { with a variety of } \\
\text { specialized equipment } \\
\text { for both on- and off- } \\
\text { road movement. }\end{array}$ & $\begin{array}{l}\text { Over the road } \\
\text { operations affected by } \\
\text { route interferences } \\
\text { and obstacles created } \\
\text { by weather, terrain, or } \\
\text { enemy action } \\
\text { sustained line-haul } \\
\text { operations over long } \\
\text { distances un- } \\
\text { economical in terms } \\
\text { of ton-mile output } \\
\text { versus expenditure of } \\
\text { manpower and } \\
\text { equipment. }\end{array}$ \\
\hline
\end{tabular}




\begin{tabular}{|c|c|c|c|}
\hline $\begin{array}{l}\text { ORDER OF } \\
\text { ECONOMY }\end{array}$ & $\begin{array}{l}\text { MOST EFFECTIVE } \\
\text { USE }\end{array}$ & CAPABILITIES & LIMITATIONS \\
\hline $\begin{array}{l}\text { Army Air (Rotary- } \\
\text { Wing) }\end{array}$ & $\begin{array}{l}\text { The most costly Army } \\
\text { mode for the } \\
\text { movement of } \\
\text { supplies. Becomes the } \\
\text { primary mode of } \\
\text { transport when all } \\
\text { others are ineffective } \\
\text { because of limitations } \\
\text { or physical } \\
\text { restrictions. Used to } \\
\text { move only those high- } \\
\text { priority items and } \\
\text { critically needed } \\
\text { supplies, such as class } \\
\text { V, III, I, IX, or as } \\
\text { selected by mode } \\
\text { managers. }\end{array}$ & $\begin{array}{l}\text { All terrain. Effective } \\
\text { over short distances } \\
\text { less than } 40 \mathrm{~km} \text { for } \\
\text { external loads. } \\
\text { Helicopter can use } \\
\text { unimproved pickup } \\
\text { zone and landing zone } \\
\text { during external lift } \\
\text { operations. } \\
\text { CAPABLE OF } \\
\text { LIFTING NEARLY } \\
\text { ANY LOAD THAT } \\
\text { CAN BE SAFE-LY } \\
\text { RIGGED and that is } \\
\text { WITHIN THE } \\
\text { WEIGHT limitations } \\
\text { of the helicopter. CH- } \\
47 \text { helicopters are } \\
\text { capable of using Air } \\
\text { Force } 463 \mathrm{~L} \text { pallets } \\
\text { and standard NATO } \\
\text { warehouse pallets, } \\
\text { when they are } \\
\text { equipped with the } \\
\text { helicopter internal } \\
\text { cargo handling } \\
\text { system. }\end{array}$ & $\begin{array}{l}\text { Operational } \\
\text { capabilities limited by } \\
\text { weather. Restricted } \\
\text { flights in snow } \\
\text { conditions and } \\
\text { thunderstorms. } \\
\text { Freezing levels above } \\
\text { surface may limit } \\
\text { capabilities. Aircraft } \\
\text { capabilities limited by } \\
\text { cargo load weight, } \\
\text { cargo hook limits, or } \\
\text { cargo door sizes. } \\
\text { Aircraft availability } \\
\text { may be affected by } \\
\text { flying hour program } \\
\text { or crew rest } \\
\text { requirements. Internal } \\
\text { cargo loading may } \\
\text { require MHE. }\end{array}$ \\
\hline $\begin{array}{l}\text { Army-Fixed-Wing } \\
\text { Army Air Force }\end{array}$ & $\begin{array}{l}\text { Complementary mode } \\
\text { for expediting move- } \\
\text { ment of mission } \\
\text { essential traffic, } \\
\text { primary or major } \\
\text { supplementary mode } \\
\text { when terrain reduces } \\
\text { effectiveness of } \\
\text { surface modes, } \\
\text { scheduled operation is } \\
\text { most economical } \\
\text { method of } \\
\text { employment and } \\
\text { produced greatest } \\
\text { sustained ton-mile } \\
\text { capability. }\end{array}$ & $\begin{array}{l}\text { Greatest potential } \\
\text { speed of delivery, } \\
\text { most flexible with } \\
\text { respect to terrain } \\
\text { obstacles, } \\
\text { economically more } \\
\text { favorably (when these } \\
\text { factors are combined } \\
\text { with substantial lift } \\
\text { capability and air } \\
\text { transport over long } \\
\text { distances). } \\
\text { Capabilities are: } \\
\text { heavy drop, container } \\
\text { delivery system, low } \\
\text { altitude parachute } \\
\text { extraction system, } \\
\text { airland, adverse } \\
\text { weather aerial } \\
\text { delivery system, aerial } \\
\text { bulk fuel delivery } \\
\text { system. }\end{array}$ & $\begin{array}{l}\text { Requires the } \\
\text { availability of } \\
\text { airfields. For other } \\
\text { limitations see the } \\
\text { preceding Army air } \\
\text { limitations }\end{array}$ \\
\hline
\end{tabular}


APPENDIX 2 - Heliplane Comparison

\begin{tabular}{|c|c|c|c|}
\hline & $\begin{array}{c}\text { CarterCopter } \\
\text { Heliplane } \\
\text { Transport }\end{array}$ & $\begin{array}{l}\text { C-130J-30 } \\
\text { Hercules }\end{array}$ & $\begin{array}{c}\mathrm{CH}-47 \mathrm{~F} \\
\text { Chinook ICH }\end{array}$ \\
\hline \multicolumn{4}{|l|}{ Dimensions } \\
\hline Wingspan & $125 \mathrm{ft}$ & $132 \mathrm{ft} 7$ inches & N/A \\
\hline Wing area & $969 \mathrm{sq}^{2}$ & $1,745 \mathrm{sq}^{2}$ & $\mathrm{~N} / \mathrm{A}$ \\
\hline Wing aspect ratio & $\begin{array}{l}16.1: 1 \text { (very } \\
\text { efficient) }\end{array}$ & $10.1: 1$ & $\mathrm{~N} / \mathrm{A}$ \\
\hline Rotor diameter & $150 \mathrm{ft}$ & $\mathrm{N} / \mathrm{A}$ & $60 \mathrm{ft} \times 2$ \\
\hline Rotor blade area & $868 \mathrm{ft}^{2}\left(4 \times 217 \mathrm{ft}^{2}\right)$ & $\mathrm{N} / \mathrm{A}$ & \begin{tabular}{|l}
$480 \mathrm{ft}^{2}\left(3 \times 80 \mathrm{ft}^{2} \mathrm{x}\right.$ \\
$2)$ \\
\end{tabular} \\
\hline AC overall length & $106 \mathrm{ft}$ & $112 \mathrm{ft} 9$ inches & $52 \mathrm{ft} 1$ inch \\
\hline AC height & $43 \mathrm{ft}$ & $38 \mathrm{ft} 10$ inches & $18 \mathrm{ft} 11.5$ inches \\
\hline Propeller diameter & $24 \mathrm{ft}$ & $13 \mathrm{ft} 6$ inches & $\mathrm{N} / \mathrm{A}$ \\
\hline $\begin{array}{l}\text { Cargo volume } \\
\mathrm{W} \times \mathrm{H} \times \mathrm{L}\end{array}$ & $\begin{array}{l}11,033 \mathrm{ft}^{3} \\
12^{\prime} \times 10.5^{\prime} \times 65.5^{\prime}\end{array}$ & $\begin{array}{l}6,022 \mathrm{ft}^{3} \\
10.25^{\prime} \times 9^{\prime} \times 58^{\prime}\end{array}$ & \begin{tabular}{|l}
$1,474 \mathrm{ft}^{3}$ \\
$8.25^{\prime} \times 6.5^{\prime} \times 30.5^{\prime}$
\end{tabular} \\
\hline $\begin{array}{l}\text { Paratroops / Combat } \\
\text { troops }\end{array}$ & $102 / 140$ & $92 / 128$ & ?/33 \\
\hline Medical litters & 100 & 97 & $\mid 24$ \\
\hline Propulsion & Kuznetsov & Rolls-Royce Allison & $\mid \begin{array}{l}\text { Lycoming } \\
\end{array}$ \\
\hline Engines & $3 \times \mathrm{NK}-12 \mathrm{MV}$ & $4 \times$ AE 2100D3 & $2 \times 155-L 712 \mathrm{SSE}$ \\
\hline Engine rating & 14,795 shaft HP & 4,591 shaft HP & \begin{tabular}{|l}
3,137 SHP \\
continuous \\
4,378 SHP takeoff
\end{tabular} \\
\hline Propellers & $\begin{array}{l}\text { CarterCopter 4- } \\
\text { blade w/ } \\
\text { Computerized } \\
\text { Controller }\end{array}$ & $\begin{array}{l}\text { Dowty Aerospace } \\
\text { 6-blade, all } \\
\text { composite }\end{array}$ & $\mathrm{N} / \mathrm{A}$ \\
\hline \multicolumn{4}{|l|}{ Weight } \\
\hline $\begin{array}{l}\text { Operating weight } \\
\text { empty }\end{array}$ & $90,000 \mathrm{lbs}$ & 79,291 lbs & 23,402 lbs \\
\hline $\begin{array}{l}\text { Design takeoff weight } \\
\text { (max GW) }\end{array}$ & $\begin{array}{l}\text { VTOL: } 160,000 \text { lbs } \\
\text { @ 7,000 ft den. alt. } \\
\text { STOL: } 200,000 \text { lbs } \\
\text { @ 7,000 ft den. alt. }\end{array}$ & $\begin{array}{l}155,000 \mathrm{lbs} \\
(175,000 \mathrm{lbs})\end{array}$ & $\begin{array}{l}46,000 \mathrm{lbs} \\
(50,000 \mathrm{lbs})\end{array}$ \\
\hline \multicolumn{4}{|l|}{ Performance } \\
\hline $\begin{array}{l}\text { Economic cruising } \\
\text { speed }\end{array}$ & 450 MPH @ 32.5K & 390 MPH @ 28K & $159 \mathrm{MPH}$ \\
\hline Range/Payload & 800 miles / & 3,260 miles / & 115 miles / \\
\hline
\end{tabular}




\begin{tabular}{|l||l||l||l||}
\hline \hline & $\begin{array}{c}\text { CarterCopter } \\
\text { Heliplane } \\
\text { Transport }\end{array}$ & \multicolumn{1}{|c||}{$\begin{array}{c}\text { C-130J-30 } \\
\text { Hercules }\end{array}$} & \multicolumn{1}{|c|}{$\begin{array}{c}\text { CH-47F } \\
\text { Chinook ICH }\end{array}$} \\
\hline \hline & 45,000 lbs VTOL & $38,061 \mathrm{lbs}$ & $22,798 \mathrm{lbs}$ \\
\hline \hline $\begin{array}{l}\text { Ferry Range } \\
\text { (fuel only) }\end{array}$ & VTOL: 5,000 miles & 5,200 miles & 1,259 miles \\
\hline Cost & $\$ 100 \mathrm{M}$ (est.) & $\begin{array}{l}\$ 85.6 \mathrm{M} \\
\text { (C-130J) }\end{array}$ & $\$ 10.3 \mathrm{M}$ \\
\hline \hline
\end{tabular}


APPENDIX 3 Legacy Force CSS and Associated Maneuver Commander
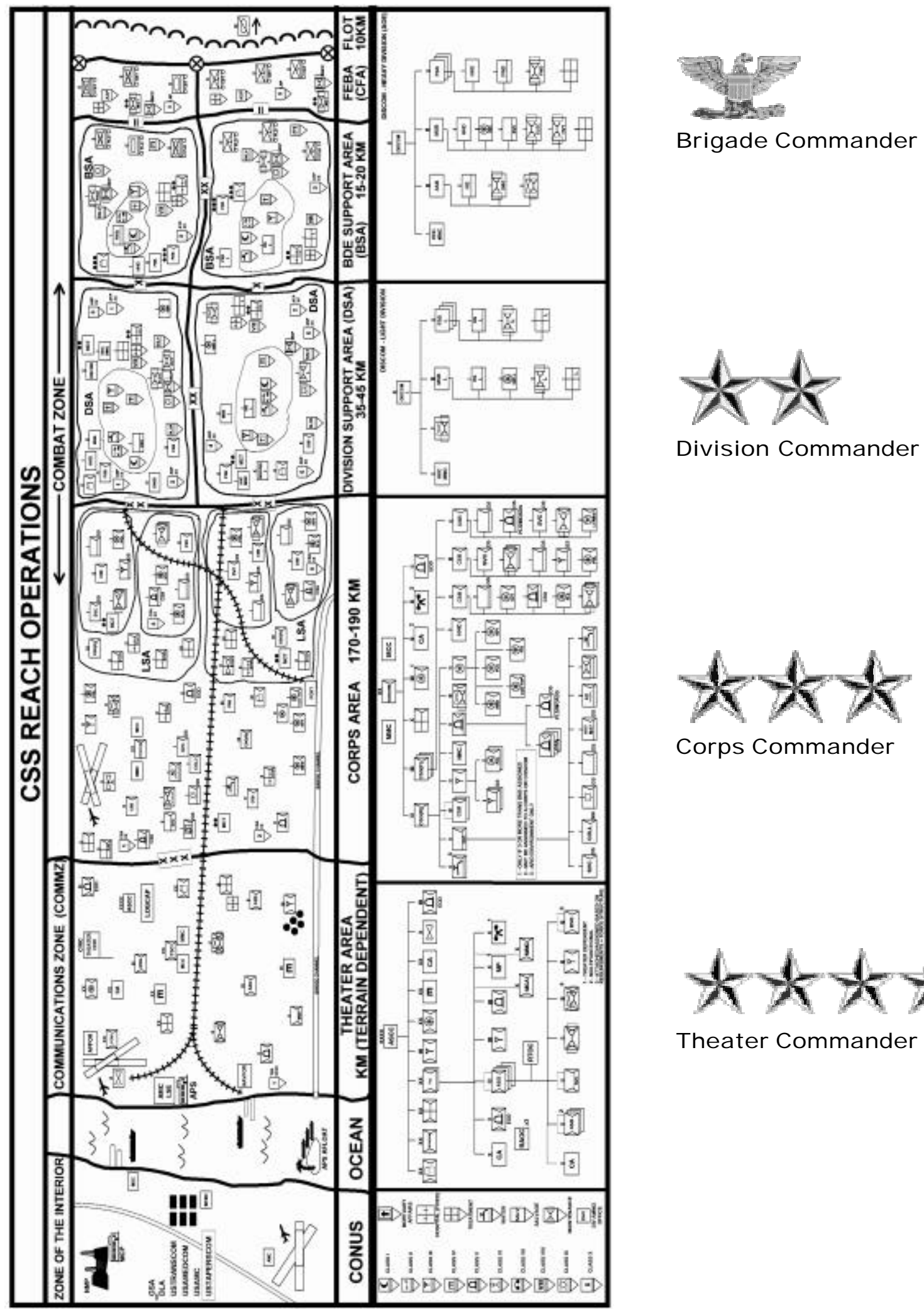

Division Commander

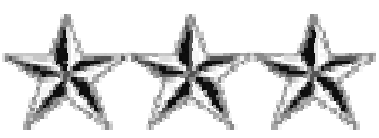

Corps Commander

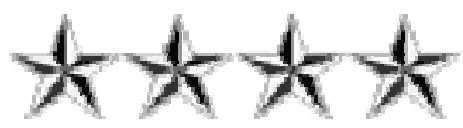

Theater Commander 


\section{BIBLIOGRAPHY}

9th Infantry Division. Motorized Experience of the 9th Infantry Division 1980-1989. Fort Lewis, 1989.

CarterCopters. 3 Jan. 2002 <http://www.cartercopters.com/>.

Cassidy, Joseph F. C-130 Transportability of Army Vehicles. N.p.: Military Traffic Management Command Transportation Engineering Agency, 2001.

Clark, Wesley K. Waging Modern War. New York: PublicAffairs, 2001.

Central Intelligence Agency. CIA World Fact Book. 10 Mar. 2002 $<$ http://www.cia.gov/cia/publications/factbook/>.

Department of Defense. Directive Number 5100.1: Functions of the Department of Defense and Its Major Components. By Deputy Secretary of Defense. Washington, DC, 1987.

Department of Defense. Joint Publication 1-02, Department of Defense Dictionary of Military and Associated Terms. By Chairman of the Joint Chiefs of Staff. Washington, D.C.: US Government Printing Office, 2001.

Department of Defense. Joint Publication 40 Doctrine for Logistics Support of Joint Operations. By Director for Logistics (J-4). Washington, DC, 2000.

Department of Defense. Joint Vision 2020. By Chairman of the Joint Chiefs of Staff. Washington, D.C.: US Government Printing Office, 2000.

Department of Defense. Report on Allied Contributions to the Common Defense. By Secretary of Defense. 2001.

Department of the Army. Aerial Resupply of the Armored Division. By Roy Moore, et al. Fort Knox: Armored School, 1952.

Department of the Army. Air Resupply of Armored Units. By MAJ John T. Pierce III, et al. Fort Knox: Armored School, 1953.

Department of the Army. Army Vision. By GEN Eric K. Shinseki. Washington, DC, 1999. Oct. $1999<$ https://www.us.army.mil/csa/vision.html>.

Department of the Army. Field Manual 1 The Army. Washington, DC, 2001.

Department of the Army. Field Manual 1-100 Army Aviation Operations. Washington, DC, 1997.

Department of the Army. Field Manual 3-0 Operations. Washington, DC, 2001.

Department of the Army. Field Manual 55-1 Transportation Operations. Washington, DC, 1995. 
Department of the Army. Field Manual 55-15 Transportation Reference Data. Washington, DC, 1997.

Department of the Army. Field Manual 63-3 Corps Support Command. Washington, DC, 1993.

Department of the Army. Field Manual 100-10 Combat Service Support. Washington, DC, 1995.

Department of the Army. Field Manual 100-10-1 Theater Distribution. Washington, DC, 1999.

Department of the Army. Field Manual 100-16 Army Operational Support. Washington, DC, 1995.

Department of the Army. White Paper: Concepts for the Objective Force. Washington, DC, 2001. 12 Nov. 2001

<http://www.army.mil/features/WhitePaper/ObjectiveForceWhitePaper.pdf>.

Echevarria II, Antulio J. "Fusing Airpower and Land Power in the Twenty-First Century: Insights from the Army after Next." Aerospace Power Journal Fall 1999. 1 Apr. 2002 <http://www.airpower.maxwell.af.mil/airchronicles/apj/apj99/fal99/echevar.html>.

Fravel, LTC Ira F. "Freight Above the Clouds." Editorial. Quartermaster Journal June 1924: 29-32.

Harman, COL Larry L. "Sustaining the Objective Force." CASCOM CSS Battle Lab. 6 Aug. 2001. PowerPoint Briefing

Jalali, Ali Ahmad, and Lester W. Grau. The Other Side of the Mountain: Mujahideen Tactics in the Soviet-Afghan War. N.p., 1995.

Krepinevich, Andrew F. The Army and Vietnam. Baltimore: The Johns Hopkins University Press, 1986.

Lambeth, Benjamin S. NATO'S Air War For Kosovo: A Strategic and Operational Assessment. Rand, 2001. 9 Mar. $2002<$ http://www.rand.org/publications/MR/MR1365/>.

Langenus, Peter C. "Moving an Army: Movement Control for Desert Storm." Military Review Sept. 1991: 40-51. 8 Jan. 2002 <https://calldbpub.leavenworth.army.mil/eng_mr/text/Vol71/00000009/art041_8.pdf\#xm l=https://calldbpub.leavenworth.army.mil/temp_dir/hltd414F2737.pdf>.

Lynch, Rick. Digital Brigade - Lessons Learned. N.p., 1999. This book was issued to US Army Command and General Staff College students taking the Digital Division (A308/A408) course during academic year 2000-2001.

Lynch, Rick. Personal Interview. Summer 1999.

Mahan, LTG Charles S. "CS/CSS Transformation." Deploying, Supporting and Sustaining the Force Web Site. 3 Apr. 2001. PowerPoint Briefing. http://www.hqda.army.mil/logweb/directorates/pl/Transformation\%20LO9/CSS\%20TRA NS\%202001\%20-\%203\%20APR\%2001.ppt 
Mahan, LTG Charles S. "Transforming to the Objective Force.” Objective Force Task Force Web Site. AUSA Symposium. Washington, DC. 8 Nov. 2001. PowerPoint Briefing. http://www.objectiveforce.army.mil/oftf/Briefings/AUSA/LTG\%20Mahan.zip

Moller International. 2 Jan. 2002 <http://www.moller.com/>.

Shinseki, GEN Eric K. "CSA Remarks," Speech presented to the Association of the United States Army Seminar. Washington, DC. 8 Nov. 2001. http://www.army.mil/leaders/csa/speeches/20011108CSAREMARKSAUSA.doc

Smith, Eric E. “A Logistics-Focused NTC Rotation.” Army Logistician Sept. 1999. 1 Apr. 2002 <http://www.almc.army.mil/ALOG/issues/SepOct99/MS473.htm>.

Solomon, LTG Billy K. "Reducing the Logistics Footprint in Support of the Objective Force." AUSA Symposium. 8 Nov. 2001. PowerPoint Briefing

Thompson, Julian F. Lifeblood of War: Logistics in Armed Conflict. London: Brassey's, 1991.

United States Army Combined Arms Support Command. Theater Distribution CD 111-24. CD-ROM. Fort Lee.

United States Army Command and General Staff College. Combat Service Support Battle Book (former G1/G4 Battle Book). By Director, Department of Logistics and Resource Operations. Fort Leavenworth, 2001.

United States Army Combined Arms Support Command. CASCOM After Action Report (AAR) for Army Transformation War Game 2001 (ATWG 2001). Fort Lee: CASCOM, 2001.

United States Army Deputy Chief of Staff G4, Directorate for Plans, Operations and Logistics Automation. LO9 Main: Deploying, Supporting and Sustaining the Force. 3 Mar. 2002 <http://www.hqda.army.mil/logweb/directorates/pl/Transformation\%20LO9/LO9_main.h $\mathrm{tm}>$.

United States Army Objective Force Task Force. Home Page. 1 Apr. 2002 $<$ http://www.objectiveforce.army.mil/oftf/pages/pao_themes_and_messages.html >.

United States Army Training and Doctrine Command. TRADOC Pamphlet 525-3-0, The United States Army Objective Force Operational and Organizational Concept (Draft 11 Nov 01). Fort Monroe, 2001.

United States Army Training and Doctrine Command. TRADOC Pamphlet 525-3-90, The United States Army Objective Force Tactical Operational and Organizational Concept for Maneuver Units of Action (Draft 7 Nov 01). Fort Monroe, 2001.

United States Army Training and Doctrine Command. TRADOC Pamphlet 525-4-0, The United States Army Objective Force Maneuver Sustainment Operational and Organizational (O\&O) Concept (Draft 11 Feb 2002). By CASCOM CSS Battle Lab. Fort Monroe, 2002.

United States Army Training and Doctrine Command. TRADOC Pamphlet 525-66, Future Operational Capability. Fort Monroe, 1997. 
United States Army Training and Doctrine Command. Objective Force Unit of Employment Draft Concept. By Joint and Army Concepts Directorate Deputy Chief of Staff for Doctrine. 15 Aug 2001. PowerPoint Briefing

United States Transportation Command. Mobility Requirements Study 2005. 2001.

US Army TACOM - Rock Island Aircraft Armament And Small Arms Commodity Business Unit. US Army Helicopter Info. 6 Mar. 2002 <http://www-acala1.ria.army.mil/lc/cs/csa/aptoc.htm\#AH64D>.

US Army Training and Doctrine Command. Future Operational and Threat Environment: A View of the World in 2015. By Deputy Chief of Staff for Intelligence. Fort Monroe, 2001.

USJFCOM J9 Joint Futures Lab. Rapid Decisive Operations. 2001.

Van Nederveen, Gilles K. "USAF Airlift into the Heart of Darkness, the Congo 1960-1978: Implications for Modern Air Mobility Planners.” Airpower Research Institute. 25 Mar. 2002 <http://research.au.af.mil/papers/special_collection/arr/2001-04.pdf〉.

Wang, Mark Y.D., and James A. Champy . "Chapter 2: Institutionalizing the Velocity Management Paradigm." Accelerated Logistics: Streamlining the Army's Supply Chain. 2000. 2000. Rand. 5-8. 25 Mar. 2002 <http://www.rand.org/publications/MR/MR1140/>. 